OPEN ACCESS

Edited by:

Sangeeta Dhawan,

City of Hope National Medical Center,

United States

Reviewed by:

Sadhan Das,

Central Drug Research Institute (CSIR),

Inês Cebola

Imperial College London,

United Kingdom

*Correspondence:

Romano Regazzi

Romano.Regazzi@unil.ch

Specialty section:

This article was submitted to

Diabetes: Molecular Mechanisms,

a section of the journal

Frontiers in Endocrinology

Received: 22 February 2021 Accepted: 20 April 2021

Published: 10 May 2021

Citation:

Jacovetti C, Bayazit MB and Regazzi $R$ (2021) Emerging Classes of Small Non-Coding RNAs With Potential Implications in Diabetes and Associated Metabolic Disorders.

Front. Endocrinol. 12:670719. doi: 10.3389/fendo.2021.670719

\section{Emerging Classes of Small Non- Coding RNAs With Potential Implications in Diabetes and Associated Metabolic Disorders}

\author{
Cécile Jacovetti ${ }^{1}$, Mustafa Bilal Bayazit ${ }^{1}$ and Romano Regazzi ${ }^{1,2 *}$ \\ ${ }^{1}$ Department of Fundamental Neurosciences, University of Lausanne, Lausanne, Switzerland, ${ }^{2}$ Department of Biomedical \\ Sciences, University of Lausanne, Lausanne, Switzerland
}

Most of the sequences in the human genome do not code for proteins but generate thousands of non-coding RNAs (ncRNAs) with regulatory functions. High-throughput sequencing technologies and bioinformatic tools significantly expanded our knowledge about ncRNAs, highlighting their key role in gene regulatory networks, through their capacity to interact with coding and non-coding RNAs, DNAs and proteins. NcRNAs comprise diverse RNA species, including amongst others PIWI-interacting RNAs (piRNAs), involved in transposon silencing, and small nucleolar RNAs (snoRNAs), which participate in the modification of other RNAs such as ribosomal RNAs and transfer RNAs. Recently, a novel class of small ncRNAs generated from the cleavage of tRNAs or pretRNAs, called tRNA-derived small RNAs (tRFs) has been identified. tRFs have been suggested to regulate protein translation, RNA silencing and cell survival. While for other ncRNAs an implication in several pathologies is now well established, the potential involvement of piRNAs, snoRNAs and tRFs in human diseases, including diabetes, is only beginning to emerge. In this review, we summarize fundamental aspects of piRNAs, snoRNAs and tRFs biology. We discuss their biogenesis while emphasizing on novel sequencing technologies that allow ncRNA discovery and annotation. Moreover, we give an overview of genomic approaches to decrypt their mechanisms of action and to study their functional relevance. The review will provide a comprehensive landscape of the regulatory roles of these three types of ncRNAs in metabolic disorders by reporting their differential expression in endocrine pancreatic tissue as well as their contribution to diabetes incidence and diabetes-underlying conditions such as inflammation. Based on these discoveries we discuss the potential use of piRNAs, snoRNAs and tRFs as promising therapeutic targets in metabolic disorders.

Keywords: PIWI-interacting RNAs (piRNAs), small nucleolar RNAs, tRNA-derived small RNAs (tRFs), diabetes, metabolism 


\section{INTRODUCTION}

The publication in 2001 of the entire Human Genome Sequence $(1,2)$ has provided new insights into the biological relevance of our genes and of their transcripts. Beside the genes that code for proteins, which represent less than $2 \%$ of the genome, more than $90 \%$ of the other sequences, considered until recently "junk" DNA, were found to be transcribed and to constitute a commensal source of RNAs of all types (3). RNAs can be classified according to their biological function and their physico-chemical properties (protein-coding messenger RNAs, ribosomal RNAs or transfer RNAs) but also according to their size (4). They are classified as small non-coding RNAs if they are shorter or long non-coding RNAs (lncRNAs) if they are longer than 200 nucleotides. Small non-coding RNAs include microRNAs (miRNAs), transfer-derived RNAs (tRFs), small nucleolar RNAs (snorRNAs), small nuclear RNAs (snRNAs), small interfering (siRNAs) and PIWI-interracting RNAs (piRNAs) while lncRNAs include also circular RNAs (cirRNAs). Some non-coding RNAs, such as miRNAs, have been extensively studied during the last two decades and their contribution to the development of a variety of pathological conditions is now well established $(5,6)$. For others, such as tRFs, snoRNAs, snRNAs, piRNAs, and cirRNAs, a key role in the regulation of numerous transcriptomic, epigenetic and proteomic events is becoming increasingly evident and an involvement in chronic human diseases, including in the etiology of diabetes and its complications, is now emerging (7).

Diabetes is a metabolic disease that currently affects 1 in 11 people worldwide, or 463 million adults, and its incidence is rising, in relationship with unhealthy lifestyles in association to genetic predisposition, and is foreseen to reach 700 million by 2045 (https://www.idf.org/). Having diabetes, strongly impacts the life quality and expectancy of patients due to increased risk of cardiac, vascular, renal and neuropathic complications. Diabetes is characterized by chronic hyperglycemia resulting from the body's inability to meet its insulin requirements. In type 1 diabetes (T1D), which accounts for approximately $10 \%$ of diabetes cases, an autoimmune response directed against pancreatic $\beta$-cells leads to a drastic loss of insulin-secreting cells and a near complete lack of the hormone (8). In type 2 diabetes (T2D), representing approximately $90 \%$ of the diabetes cases, patients present a loss of $\beta$-cell function and/or a resistance of the target tissues (liver, muscle and adipose tissue) to insulin action (9). In order to maintain stable and homeostatic glycemic levels (below $1.4 \mathrm{~g} / \mathrm{l} 1.5$ hours after a meal), T1D patients require subcutaneous injections of insulin while individuals suffering from T2D take oral medications to improve insulin sensitivity, in some cases supplemented with insulin injections. Despite major advances in islet transplantation, the manufacture of $\beta$-cell surrogates from stem cells, and insulin molecules with an action very close to that of endogenous human insulin, there is at present no curative treatment for this pathology. In this field, research is very active with the hope to better characterize all the mediators and actors involved in the control of $\beta$-cell function in order to develop therapeutic strategies that target specifically the dysfunctional pathways responsible for the disease.
Herein, we will focus on three classes of small non-coding RNAs, piRNAs, snoRNAs and tRFs that have so far been less intensively studied, especially in the context of pathologies associated with metabolic disorders. Nevertheless, in view of the available information about their biological relevance, their mechanism of action and their regulation, there is growing interest for the involvement of these three classes of ncRNAs in human diseases, including in metabolic disorders.

In this review, we will discuss the biogenesis of piRNAs, snoRNAs and tRFs while emphasizing on novel sequencing technologies that allow ncRNA discovery and annotation. We will also present the mechanisms of action described so far for each of these categories of small non-coding RNAs. Finally, we will focus on current studies that demonstrate a role for piRNAs, snoRNAs and tRFs in the pathogenesis of diabetes and associated metabolic disorders.

\section{BIOGENESIS AND PROFILING OF piRNAs, snoRNAs and tRFs}

\section{piRNA Biogenesis}

P-element Induced Wimpy Testis (PIWI)-interacting RNAs (piRNAs) are 21-35 nucleotide-long RNAs that interact with the Piwi subfamily of Argonaute proteins. piRNAs are typically phosphorylated at 5' end, and 2-O-methylated at the 3' end. The piRNA pathway is highly enriched in foetal germ cells where it is required for repressing transposon activity, thereby maintaining genome integrity and ensuring faithful gametogenesis (10). A second cluster of piRNAs is expressed in postnatal sperm cells and lack transposon sequences. These piRNAs are reported to function like miRNAs and regulate meiotic gene expression (11). Accordingly, a growing body of evidence suggests somatic expression and function of piRNAs (12-14).

Unlike other Argonaute-associated small ncRNAs, such as miRNAs and short interfering RNAs (siRNAs), piRNAs originate from single-stranded RNA precursors called piRNA clusters and do not require the endoribonuclease Dicer for maturation. In most metazoans, piRNA loci are unidirectionally transcribed (15). These piRNA precursors are transported from the nucleus to the cytoplasm where they are matured into primary piRNAs through a series of enzymatic processes. First, the secondary structures of the piRNA precursors are resolved by the RNA helicase Moloney leukemia virus 10-like 1 (MOV10L1). Subsequently, the unwound piRNAs are cleaved by the endonuclease Zucchini (Zuc), generating prepiRNAs containing a 5 ' monophosphate. These pre-piRNAs are loaded onto PIWIs that facilitate the exonuclease-mediated trimming, producing piRNAs of specific lengths. Finally, Hen1, an RNA 2-O-methyltransferase, methylates the 2' oxygen at the 3' end of the piRNA, which stabilizes the piRNA structure (15). In the germline, these primary piRNAs are amplified further by a biogenesis cycle termed ping-pong loop (16). This cytoplasmic series of events are initiated when these primary piRNAs bind to the Aub subclass of Argonaute proteins. As Aub-piRNA complex induces endonucleolytic cleavage of the target transposons, they 
also generate sense-strand secondary piRNAs. Secondary piRNAs are incorporated by Ago3 and used for cleaving piRNA cluster transcripts, producing precursor piRNAs that are fed into the loop (16).

\section{piRNA Detection}

Identification and annotation of new piRNAs usually rely on immunoprecipitation of PIWI and analysis of pulled down molecules by RNA-sequencing $(17,18)$. However, this method is laborious and can be insensitive for detecting lowly expressed piRNAs. Computational methods provide a viable option for de novo piRNA annotation. The initial algorithm built to predict novel piRNAs was based on $k$-mer motifs (19). This algorithm provides $>95 \%$ accuracy and $>60 \%$ sensitivity. Subsequently, Piano and piRNAPredictor, software based on support vector machine and weighted ensemble, were developed $(20,21)$. Although they are 95\% accurate in predicting transposonrelated piRNAs, they are not optimized to detect somatic piRNAs. Alternatively, piRPred uses a combination of sequence features ( $k$-mer motifs and 5' uridine position) and genomic information to achieve $86 \%$ and $89 \%$ prediction accuracy in human and fruit fly data, respectively (22). Recently, piRNN, a program based on a convolutional neural network classifier and $k$-mer encoding strategy was developed using C. elegans, D. melanogaster, rat and human piRNAs as training models. This tool is reported to achieve at least $94 \%$ accuracy, precision, and specificity, highlighting the advancement of bioinformatic tools in piRNA annotation (23).

\section{snoRNA Processing Pathways}

SnoRNAs are intermediate-sized (60-300nt), closed-loop, nonpolyadenylated RNA molecules, well-conserved, mainly located in the nucleolus and detected in all eukaryotic organisms (24, 25). The nucleolus is the largest and most studied nuclear body, high place of ribosomal RNA (rRNAs) synthesis and processing and ribosome assembly $(26,27)$. SnoRNAs play a vital role by ensuring modifications such as pseudouridylation (Y) (class 1 of snoRNAs) or 2'-O-methylation (2'Ome) (class 2 of snoRNAs) on different RNA types, mainly rRNAs, tRNAs and small nuclear RNAs (snRNAs). These two classes of RNAs account for more than $85 \%$ of cellular RNA and their modifications are needed for their stability and function, thus giving snoRNAs a primordial place (28).

In yeast and plants snoRNAs are mostly transcribed from their own independent genomic regions, whereas in animals most snoRNA-coding sequences are intronic. When they are generated from independent DNA regions, snoRNAs are transcribed from monocistronic (under control of their own promoters via RNA polymerase II or III) or polycistronic (via RNA polymerase II) regions $(25,29)$. The 5 ' end of the transcripts is either removed or given a trimethylguanosine $(\mathrm{m} 2,2,7 \mathrm{G})$ cap before undergoing a maturation process of the 3' end ensuring the production of mature and functional snoRNAs. RNA polymerase II ensures the transcription of snoRNAs produced from introns under the control of the promoters of their host genes. In this case, snoRNA transcripts undergo splicing and debranching of the snoRNAcontaining intron followed by trimming by exonuclease enzymes $(29,30)$.

SnoRNAs are classified into two categories defined according to highly conserved sequences known as "boxes", which are present in pairs on each snoRNA molecule (31). This allows to distinguish $\mathrm{C} / \mathrm{D}$ and $\mathrm{H} / \mathrm{ACA}$ box snoRNAs. The structure of $\mathrm{C} / \mathrm{D}$ snoRNAs consists of a large closed loop which includes a $\mathrm{C}$ box (RUGAUGA motif) and a D box (CUGA motif) as well as a C' and a D' box, which are less conserved. H/ACA snoRNAs consist of two stem loops connected by the H box (ANANNA motif) and an ACA sequence in 3' position. An additional category of ncRNAs termed Cajal body-associated RNAs (scaRNAs) located in sub-nuclear structures known as Cajal bodies (32) are derived from either C/D snoRNAs displaying a long UG repeat or $\mathrm{H} / \mathrm{ACA}$ snoRNAs including an additional UAGA pattern (CAB box) $(24,33,34)$. The absence of features such as poly(A)tail and $\mathrm{m} 7 \mathrm{G}$ cap at the 5 ' end, which are structural hallmarks of mRNAs and facilitate their export into the cytosol, may explain why snoRNAs remain exclusively localized in the nucleus $(35,36)$.

Irrespective of the class to which they belong, snoRNAs associate to proteins and display a stable ribonucleoproteic structure (37). Due to their compact entanglement with protein snoRNPs, snoRNAs are highly stable structures compared to other transcripts produced by Pol II.

\section{snoRNA Identification}

The number of genes transcribed into snoRNAs increases proportionally with the complexity of the organisms, with less than a hundred genes coding for 76 snoRNAs in Saccharomyces cerevisiae to more than 500 snoRNA genes in humans $(38,39)$. The techniques used to detect snoRNAs are critical to ensure the specificity of the identification (40). SnoRNAs are easily quantifiable by conventional qPCR after being reverse transcribed (RT) by random priming. Although, RNAsequencing in combination with bioinformatics allow a very accurate estimation of gene expression and the de novo construction of the transcriptomic landscape, conventional approaches such as semi-quantitative northern blotting and RNase protection assay (RPA) are still being used to validate genomic analyses (41). In silico techniques estimate the population of snoRNAs to exceed thousands of candidates in mammalian cells $(42,43)$. The majority of human snoRNAs are produced from mRNA introns or IncRNAs. Several studies have observed that the expression of snoRNAs released from spliced introns does not always correlate with the mRNA level of the host gene (44-46). A large proportion of the host genes from which snoRNAs are transcribed code for mRNAs or lncRNAs that are non-functional and are destined to be degraded by the nonsense-mediated RNA decay pathway (44). This makes snoRNA production an actively regulated process for functional and biological purposes. This area of research still includes many open questions and further studies will be necessary to clarify the relationship between snoRNAs and their hosting genes. 


\section{tRF Synthesis}

Transfer RNAs (tRNAs) are 73-90 nucleotide long RNAs that help decode mRNA sequences into proteins. Their role as amino acid carriers during protein translation is well documented. tRNAs are the most abundant cellular RNAs, comprising approximately $12 \%$ of total RNA in most cells $(47,48)$. Due to the degeneration of the genetic code, several codons code for the same amino acid. Indeed, the standard genetic code consists of 64 codons corresponding to 20 different amino acids. There are more than 260 different tRNAs in humans that are generated from more than 400 nuclear genes (49). Furthermore, mitochondrial DNA encodes for 22 additional tRNAs (mttRNAs) (50). This large number of tRNA molecules is due to the presence of isoacceptors (tRNAs carrying the same amino acid but consisting of a different nucleotide sequences in the body and in the anticodon region) and isodecoders (tRNAs sharing the same anticodon and carrying the same amino acid but with a different nucleotide sequence in the body). Isoacceptors and isodecoders are present in several copies in the genome and their expression (constituting the tRNA pool) is tissue and cell type-specific and can be modulated by stress conditions. Post-translational tRNA modifications introduce further complexity to tRNA function. These modifications may occur in the nucleus, cytoplasm and mitochondria through the action of various tRNA modifying enzymes, and modulate base pairing, tRNA folding and/or stability (51). The average mammalian cytoplasmic and mitochondrial tRNAs contain 13 and five modified bases, respectively. tRNAs are the most stable RNAs in vivo, but hypomodified tRNAs are targeted for degradation (52). In addition to the degradation of dysfunctional tRNAs, tRNAs may also undergo endonucleasemediated fragmentation.

Both pre-tRNAs and mature tRNAs can be fragmented in concert with tRNA expression, or in response to a stress stimulus $(53-56)$. While the nomenclature of tRFs is not yet well established, six main classes of tRFs have been described. These classifications are based on the tRNA fragmentation site: tRF- $1 s$ are generated from pre-tRNAs, tRF-3/5s from distal ends of mature tRNAs, tiRNA-3/5s from the cleavage of anticodon sites of mature tRNAs, and i-tRFs from internal sequences of mature tRNAs (Figure 1). While Angiogenin is the main enzyme responsible for cleaving the anticodon site, different endonucleases have been reported to generate other classes of tRFs, including Dicer, SLNF13, RNase T2, and RNase Z (30, $55,57)$.

\section{Detection and Annotation of tRFs}

Like other ncRNAs, detection of tRFs has been substantially improved by the advancement of high-throughput small RNA sequencing. The fragments can be annotated by aligning the sequencing data to mature and pre-tRNA sequences using publicly available genomic tRNA databases, such a GtRNAdb (58). This permitted to reveal the tRF landscape under various physiological and pathological conditions, paving the way for functional studies (59). However, detection of tRFs by smallRNA sequencing has certain limitations that need to be overcome. First, certain post-translational modifications that decorate tRNAs, such as 3' end aminoacylation and various methylations, may interfere with adaptor ligation and cDNA synthesis, leading to sequencing biases (60). To overcome this issue, RNA samples can be pre-treated with specific enzymes that remove these post-translational modifications $(60,61)$. Second, tRFs detected by sequencing need to be distinguished from random degradation products of tRNAs. Genuine tRFs can be predicted by using a binomial test, a statistical method that normalizes the tRF levels with theoretically expected levels of degradation products (62). Finally, the presence of tRNA isodecoders which share extended regions of similarity can prevent the identification of the parent tRNA (63).

Concurrent with the growing high-throughput data, several tRF databases and bioinformatic tools have been developed. Databases such as MINTmap and tRF2Cancer extract and catalogue raw and normalized tRF levels from published human small RNA-seq data under physiological and pathological conditions $(62,63)$. tRF2Cancer and sRNAtools further provide tRF identification from user uploaded sequencing data (64).

\section{BIOLOGICAL ROLES OF piRNAs, snoRNAs AND tRFs AND METHODS TO DETERMINE THEIR FUNCTIONS}

\section{Mechanisms of piRNA Function}

The ancestral function of piRNAs in most animals is to provide post-transcriptional control of mRNA transposons and thus repress transposon mobilization in order to perpetuate and protect the genome of germline cells (65). This mode of repression relies on the production of piRNAs via the aforementioned "ping-pong" process. Guided by the piRNAs, PIWI proteins cleave the targeted mRNAs 10 nucleotides upstream of the 5' end of the piRNA as a guide, leading to the formation of a new piRNA in the opposite direction from the 5 ' end. Thus, piRNAs belonging to the same pair generated by the ping-pong ring share 10 nucleotides at their 5 ' end (10). Nevertheless, many piRNAs have been identified that do not present any complementarity to transposable elements (TE), suggesting that they may have a different mechanism of action (66).

The presence of transposons within the genome represents a potential risk of generating illegitimate recombinations, the appearance of double-stranded DNA breaks following transposon replication, their aleatory insertion causing an alteration in the sequence of coding genes as well as the ectopic expression of neighboring genes under the control of the promoter of the inserted transposons $(67,68)$. piRNAs exerts a protective effect against the insertion of transposons mainly in germ cells. They act by binding to PIWI proteins and guiding them to the transcribed nascent transposon, which are then silenced (65). A large proportion of piRNAs are thus generated from TE sequences and target TE transcripts. However, a subset of piRNAs does not emanate from TE sequences but are also 


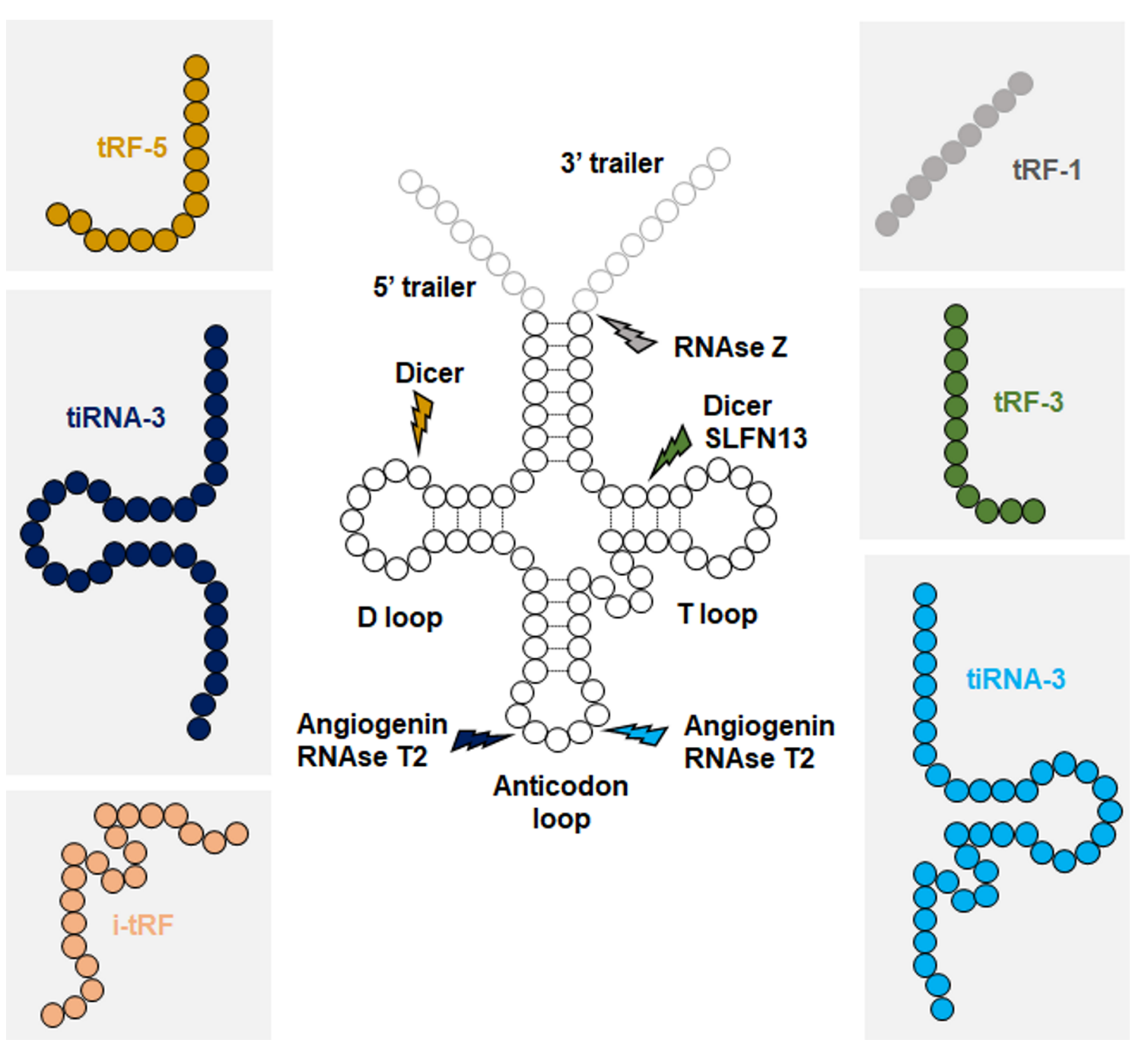

FIGURE 1 | Biogenesis of tRFs. Each class of tRFs are categorized based on where they map on tRNA sequence. tRF-1s are generated from trailer sequences present on primary tRNA transcripts (pre-tRNAs), while other classes are generated from mature tRNAs. Approximate cleavage positions and the responsible endonucleases for each class of tRFs are indicated.

produced during spermatogenesis. These piRNAs, called prepachytene, are present in male gonad germ cells before birth and during the neonatal period and silence the TE using the mechanism described above (67). Conversely, non-TE piRNAs, which appear after birth, have a different mode of action and direct PIWI proteins to cleave and affect the stability of targeted mRNAs (67). However, the function of the piRNAs that do not target TE remains unclear (69).

Nevertheless, piRNAs are also produced in somatic cells where the preservation of their ancestral function seems to be questionable. For example, piRNAs expressed in invertebrate somatic cells seem to play an essential role in fighting against viral infections $(65,70,71)$. The mechanism at stake here follows the integration of the viral genome which would trigger the pingpong cycle and thus induce the production of piRNAs that recognize viral RNA causing to its degradation (71). This model is mainly described in mosquitoes and requires further research to confirm its validity in other organisms. The studies performed during the last 20 years focused on the understanding of piRNA biogenesis but also on their mode of action and their role within germ and somatic cells. However, many questions remain open. In particular, the emergence of piRNA functions that are independent of their capacity to repress transposons will need to be further explored (Figure 2).

\section{Strategies to Unveil piRNA Targets}

The function of piRNAs which do not act on transposons remain largely unknown. The limited knowledge in the field also hinders the development of prediction tools for piRNA targets. Exceptionally, piRNA targeting dynamics has started to be unveiled in C. elegans (72). Additionally, transcriptome-wide interactions between piRNAs and their targets have been 


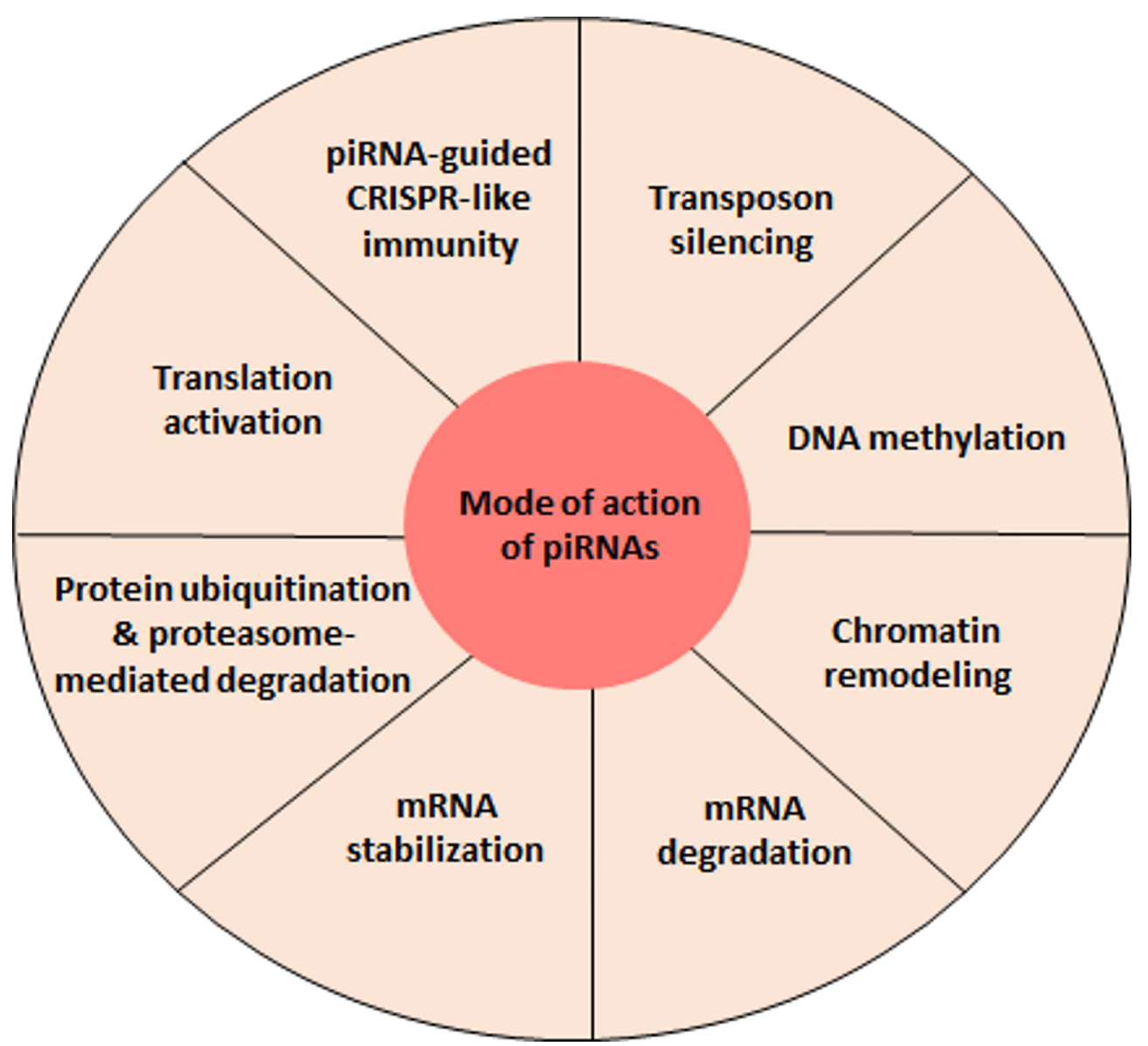

FIGURE 2 | piRNA-mediated regulatory functions. At present, the best characterized function of piRNAs is the repression of transposable elements. However, recent evidence indicates that piRNAs can accomplish a variety of other regulatory activities, findings that will most certainly be further strengthen by future studies.

identified using an in vivo cross-linking approach (CLASH) (73). Thus, these studies enabled the construction of pirScan and piRTarBase, target prediction tools for piRNAs in C. elegans (74, $75)$. With the rapid evolution in the piRNA field, similar tools are expected to be built for mammalian piRNAs, potentially contributing to unravel the function of piRNAs under normal and pathophysiological $\beta$-cell conditions.

\section{snoRNAs: Functional Relevance}

The canonical function of both snoRNAs and scaRNAs is to implement modifications, mainly methylations and pseudouridylations. SnoRNAs preferentially target ribosomal RNAs (rRNAs) and small nuclear RNAs (snRNAs), in order to ensure their maturation in the nucleus, protect them from nucleolytic degradation, thus indirectly affecting the function of the ribosome and of the spliceosome (25). The vast majority of the snoRNAs carry specific sequences complementary to various types of cellular RNAs (short sequences of 7 to 21 nucleotides called antisense element (ASE) or guide region) ensuring recognition and fine-tuning of substrate RNAs (76). SnoRNAs associate with proteins forming small nucleolar ribonucleoprotein (snoRNP) complexes. SnoRNA partner proteins are essential for their biogenesis and to ensure their stability by protecting them from exonuclease, but also to maintain their nuclear localization (76). C/ D snoRNAs induce 2-O'-methylation of targeted rRNAs at specific sites. C/D snoRNAs form snoRNPs complexes mainly with Snu13, Nop56, Nop58 and fibrillarin methyltransferase proteins. H/ACA snoRNAs induce pseudo-uridyl modifications by catalyzing the isomerization of uridine to pseudouridine. The protein partners of H/ACA boxes are the dyskerin, Nhp2, Nop10 and Gar1 factors. SnoRNAs can also be directly involved in the synthesis of rRNA precursors in the nucleolus (77). The interference of snoRNAs with ribosomes or the biogenesis of snRNAs itself can result in the alteration of protein-coding gene expression via alternative splicing or translation control (78). Along this line, a study demonstrated circadian periodicity of snoRNA expression, which is presumed to be at the origin of the rhythmic expression of translation initiation factors, ribosomal proteins and ribosomal RNAs and thus of ribosome biogenesis in mouse liver (79). The capacity of snoRNAs to be cleaved into piRNAs can also indirectly affect the regulation of the genomic and transcriptomic profile (80). A significant number of studies revealed that snoRNAs can exert a 
broader action via new emerging mechanisms including (Figure 3): (i) acetylation of rRNAs, (ii) methylation of tRNAs, (iii) competition on binding sites with other types of RNA, (iv) chromatin remodeling, (v) recruitment of the nuclear exosome, affecting the stability of pre-mRNAs, but also (vi) regulation of mRNA abundance via, among other things, the control of mRNA $3^{\prime}$ processing (81). So far, the studies that have established the function of snoRNAs have focused on the dominant role played by snoRNAs in the nucleus; however, the detection of snoRNAs in other cellular compartments suggests that these small ncRNAs may have novel and less conventional functions (82-84).

The function of a non-negligible fraction of the so-called orphan snoRNAs remains unknown due to the lack of complementarity of their ASE with any RNA sequence or to a structure that differs from conventional snoRNAs (shorter or longer or with boxes without consensus motifs or with both $\mathrm{C} / \mathrm{D}$ and H/ACA boxes) that potentially indicate a different mechanism of action $(77,85,86)$. Although certain functions have been attributed to these non-canonical factors (24), their precise role, the type of modifications they may induce and, above all, whether they are expressed at significant levels remains to be explored.

A significant degree of uncertainty remains also about a brand-new class of small RNA molecules that seem to derive from mature snoRNAs (87). Deep sequencing techniques revealed that snoRNAs can be cleaved into smaller and more stable molecules named snoRNA-derived RNAs (sdRNAs) (8891). The function of sdRNAs remains to be established, although pioneering work suggests an involvement in mRNA splicing and translation control $(92,93)$. In spite of the huge advances in deep-sequencing, many snoRNAs, sdRNAs or snoRNA-like genes have not yet been annotated and are absent from current databases (40).

\section{Techniques Used to Decrypt snoRNA Functions}

The knowledge acquired so far about the function of snoRNAs has emerged thanks to advanced techniques which we will discuss in the following paragraph. The first approaches used to elucidate the role of snoRNAs were oriented towards the detection and localization of canonical modifications (2'-Oribose methylation and pseudouridylation) on target RNAs. One strategy consists in performing a reverse transcription (RT) at high concentration of dNTPs (in low concentration of dNTPs, the reverse transcriptase stops at the nucleotide preceding the modification and thus aborts the RT) followed by high-resolution electrophoresis allowing the identification of the modified sites. Another alternative based on a similar principle, consists in using an unbiased high-throughput $2^{\prime}$-Oribose methylation profiling technique called RimSeq (43). In this case, cDNAs in which the synthesis has been prematurely stopped due to the presence of a limited concentration of dNTP, modifications are sequenced. Finally, another method, called RiboMethSeq, takes advantage of the fact that both pseudouridines previously treated with a CMC compound (carbodiimide) and phosphodiester bonds, located $3^{\prime}$ to a $2^{\prime}$ $\mathrm{O}$-methylated residue, are protected from alkaline hydrolysis. Alkaline hydrolysis induces partial fragmentation of the

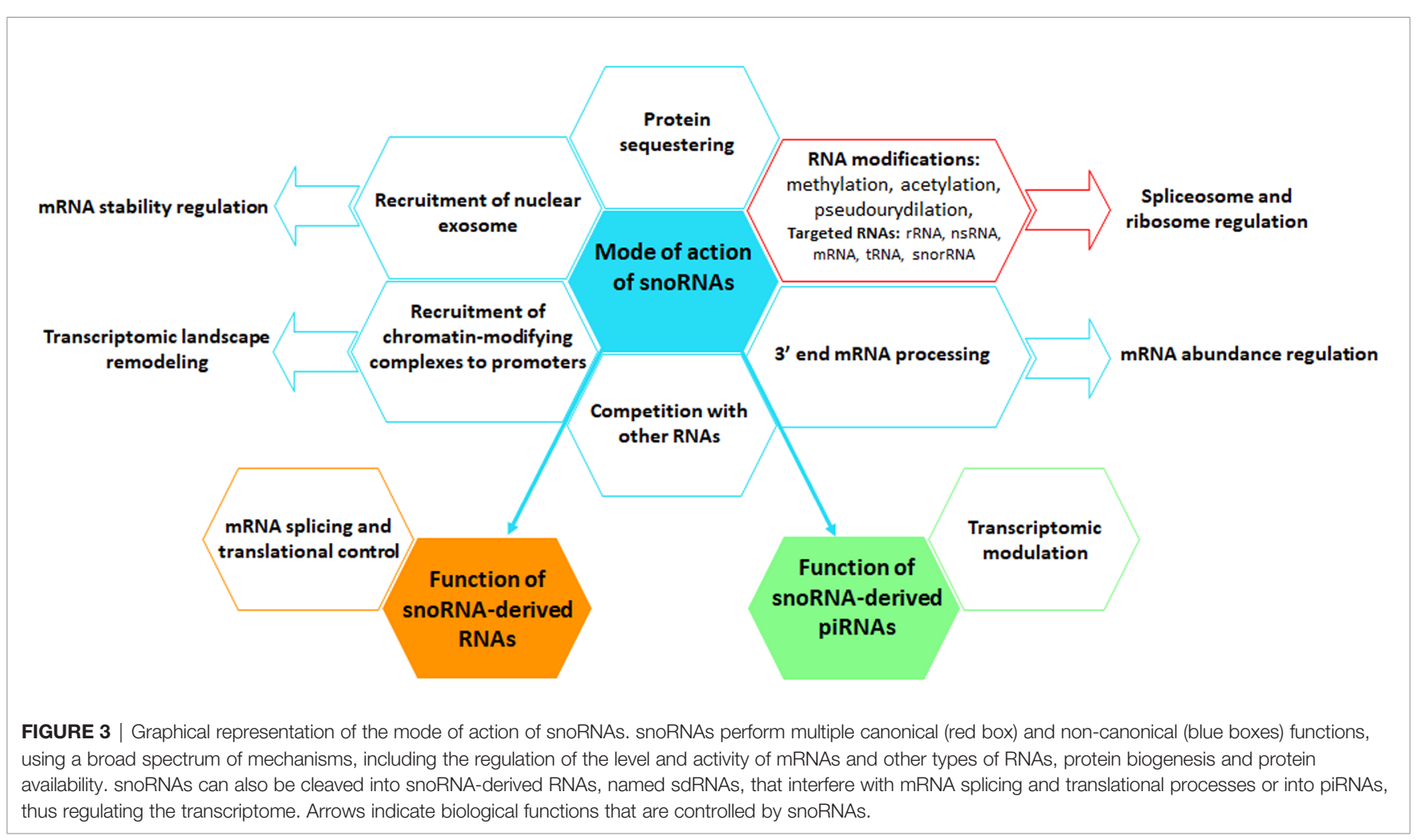


modified RNAs targeted by the snoRNAs, with preservation of the sites containing the methylations or pseudouridines, thus revealed by sequencing. When modifications in 3' regions or in several adjacent residues of snoRNAs are present, sequencing reactions are impaired and mass spectrometry techniques were used $(94,95)$.

Over the last 10 years, there has been an emergence of methods to identify the snoRNA interactome which are very promising. These techniques include CLIP (UV cross-linking and immunoprecipitation) (94, 96, 97), CLASH (cross-linking, ligation, and sequencing of hybrids) (98), PAR-CLIP (photoactivable ribonucleoside-enhanced crosslinking and immunoprecipitation) (99) and hiCLIP (RNA hybrid and individual-nucleotide resolution ultraviolet cross-linking and immunoprecipitation) (100). These methodologies are based on the use of antisense probes ensuring a selective and specific pull-down of the snoRNA of interest. The interactions between the snoRNA molecules are stabilized by exposure to ultraviolet light before proceeding with cell lysis and snoRNA sequencing allowing the identification of the snoRNAs and of their partners. In the technique known as LIGR-seq (ligation of interacting RNA followed by high-throughput sequencing), the cells are treated with the photoreactive psoralen derivative $4^{\prime}$ -aminomethyltrioxsalen (AMT) which captures RNA: RNA interactions engaged in base pairing (101). In PARIS (psoralen analysis of RNA interactions and structures), the use of S1 nuclease/RNase III enzymes induces the fragmentation of AMT-cross-linked RNA which are then analyzed in $2 \mathrm{D}$ electrophoresis (102). The SPLASH technique is very similar with the alternative of covalently binding with the RNA by a biotinylated psoralen and capturing $\mathrm{Mg}^{2+}$-fragmented cross-linked RNA segments on streptavidin beads before sequencing (103).
Finally, one of the latest technical developments has led to the COMRADES method (cross-linking of matched RNAs and deep sequencing) which again consists of a pull-down of cross-linked RNA by the use of a cell-permeable azide-modified psoralen derivative (psoralen-triethylene glycol azide) (104).

Overall, these techniques, which consist in capturing RNA: RNA interactions upstream of sequencing, have been proven effective in the identification of predicted snoRNA targets but also in the discovery of new non-canonical factors targeted by snoRNAs $(94,105,106)$.

\section{Emerging Roles and Mechanisms of Actions of tRFs}

In recent years, concurrent with the advancement of in-depth analyses of deep sequencing data, the implication of tRFs have been described in a wide array of physiological and pathological events including stem cell maturation, organ cross talk, intergenerational inheritance, metastasis, and response to viral infection (Figure 4) (59, 107-112). Diverse mechanisms of actions have been described which depend on the tRF type. Dichotomous functions of a single tRF have also been reported in different settings $(53,113)$. tRFs were shown to associate with proteins of the Argonaute (AGO) family to regulate gene expression, analogous to miRNAs. These interactions were validated in various models in vivo and in vitro, using photoactivatable ribonucleoside-enhanced crosslinking and immunoprecipitation (PAR-CLIP) of AGO1-4, co-immunoprecipitation (co-IP) of tRFs, and co-IP of various members of the AGO family (114-116).

tRFs are also implicated in translational regulation. In U2OS cells, alanine tiRNA-5 represses translation by interacting with the RNA binding protein YBX1 and displacing eIF4G/A from

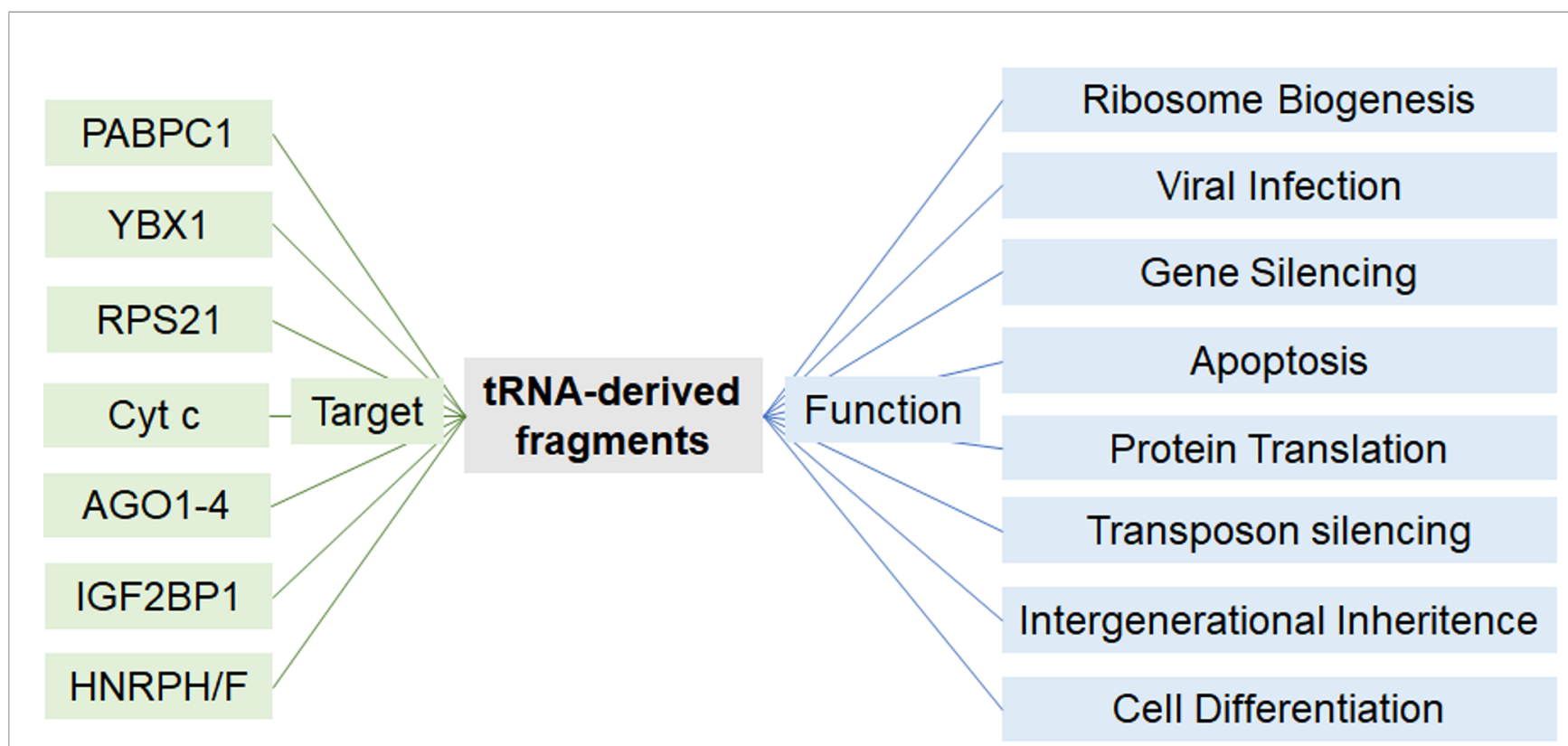

FIGURE 4 | Proposed modes of action of tRFs. Depending on the cellular setting and tRF-type, tRFs may act on different proteins to regulate a variety of cellular functions. 
capped and uncapped mRNA (117). In line with this, YBX1 PAR-CLIP in primary human breast cancer cells revealed binding to a conserved motif within glutamate, glycine, tyrosine, and aspartate i-tRFs, which destabilizes cancer transcripts by displacing YBX1 (109). Importantly, these results were supported by in vivo colonization assays in mice, where fine-tuning of tRF levels in xenografts, either by transfection of mimics or antisense LNA inhibitors, impacted metastatic colonization (109).

In sharp contrast to the role of certain tRFs in translational repression, glycine and glutamine tiRNA-5s promote translation by interacting with several ribosomal proteins including the $40 \mathrm{~S}$ ribosomal protein S21 (RPS21) (118). In this case, RPS21 interaction was first identified by an unbiased proteomic analysis of tiRNA-5 co-IP in HeLa cells, and the interaction was further confirmed when the co-IP was inversely performed, and RPS21 was used as the bait (118). Interestingly, the role of tRFs in ribosomal function was extended further when a leucine tRF-3 was shown to bind to RPS28 and RPS15 mRNAs to enhance their translation, an essential process for hepatocellular carcinoma development as illustrated both in vitro and in patient-derived orthotopic hepatocellular carcinoma model in mice (110).

\section{Databases and tRF Target Predictions}

Computational predictions of tRF targets have also been implemented in tRF research. These tools generally entail adaptations of miRNA target prediction algorithms. tRFtarget predicts mRNA targets of tRFs by combining the results of two prediction tools, RNAhybrid and IntaRNA, which rely on maximum complementary length and free energy between the small RNA and mRNA transcript (119). While these tools provide unbiased scanning of potential mRNA targets, tRFs may exert their effect solely at the proteomic level. The ATtRACT database compiles information on 370 RNA-binding proteins (RBPs) and their 1583 experimentally validated RNA-binding motifs (108). Hence, this tool may help predict potential complexes of tRFs with these well studied RBPs. In the long term, a library of target RNAs and proteins will be constructed for each tRF by compiling RNAimmunoprecipitation data across cells and tissues.

\section{ROLES OF piRNAs, snoRNAs AND tRFs IN THE PATHOGENESIS OF DIABETES AND METABOLIC DISORDERS}

\section{piRNAs and Metabolism- Related Functions}

piRNAs but also miRNAs and tRFs stand out as key mediators in the transgenerational inheritance of paternal epigenetic marks (see the section more specifically on tRFs regulation in the part named "Identified tRFs and diabetes"). The transgenerational transmission of a metabolic phenotype has been studied using a rat model in which male progenitors (F0) were fed a high-fat diet (HFD) for 12 weeks in adulthood (Figure 5A) (120). Newborns of F0 fathers fed HFD displayed reduced birth weight and pancreatic $\beta$-cell mass. Exclusively female within the F1 and F2 offspring developed glucose intolerance when the adult animals were challenged by HFD contrary to F1 and F2 females born to F0 fathers fed the control diet. Transcriptomic analysis of the sperm of F0 fathers revealed changes in the expression profile of small ncRNAs including more than thousand piRNAs. Among them, the level of three piRNAs was also changed in the sperm of F1 rats (120). Further studies are needed to understand how paternal transmission of small ncRNAs via sperm affects metabolic organs and to demonstrate a causal relationship.

Although less present in somatic cells, piRNAs are detected also in various peripheral tissues and in the central nervous system (121-123). In particular, piRNAs have been found in the fat body of adult Drosophila, an organ that bears functional analogy with mammalian liver (Figure 5B). The fat body piwi null mutant shows a reduction in fat stores with reduced triacylglycerides and glycogen content (124). piRNAs have also been identified in rat liver (125). The metabolic functions that regulate carbohydrate and lipid homeostasis are clearly disrupted in a context of diabetes. Even though there is currently no established correlation between the above-mentioned data and the impact of liver piRNA changes on the diabetic phenotype, it would be very interesting to dig in this direction. So far, there is only one published study pointing to a causal link between the deregulation of piRNAs and associated PIWI proteins and the loss of pancreatic $\beta$-cell function (12). The machinery responsible for piRNA synthesis is clearly present in pancreatic islets since two PIWI-like genes, Piwil2 and Piwil4 were identified in rat islets but also in FACS-sorted rat $\beta$-cells and their human orthologues PIWIL2 and PIWIL4 were detected in human pancreatic islets (12). Moreover, piRNAs display a dynamic expression during islet postnatal functional maturation (Figure 5C). The levels of some piRNAs were also altered in the islets of Goto-Kakizaki T2D rats. Ectopic overexpression of piRNAs up-regulated in the islets of diabetic rats alters the insulin secretory capacity of healthy $\beta$-cells. Moreover, global repression of piRNA levels in adult islet cells secondary to the silencing of piwi proteins promotes proliferation of insulin-secreting cells, known for their low replication capacity (12). The capacity of piRNAs to control replication in other cells types has already been established by various independent studies suggesting that autonomous cellular alteration of piRNA levels is associated with various cancers in mammalian models (126). The resulting loss of transposon repression could result in cancerous cell multiplication as well as a loss of hormone and growth factor action among other cellular pathways.

\section{snoRNAs in Diabetes and Metabolic Functions}

The distribution of snoRNAs appears to be specific within various tissues and sensitive to the environment (43). In response to exposure to pro-inflammatory saturated fatty acids, including palmitate, stearate or myristate, the expression of 4 snoRNAs [box C/D snoRNAs U32a (SNORD32a), U33 


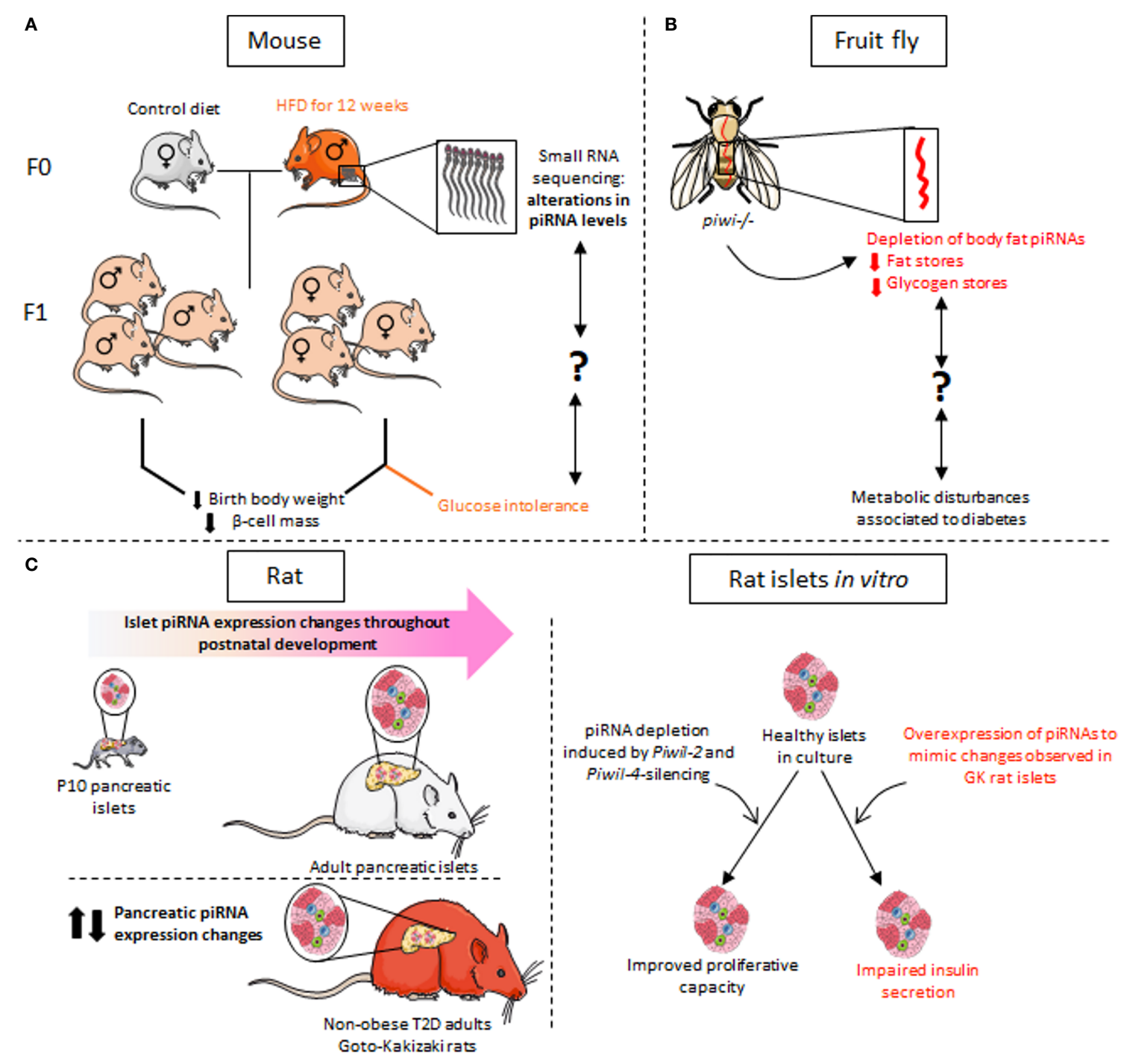

FIGURE 5 | piRNA dysregulation in the context of metabolic disorders. (A) RNA-sequencing of sperm from progenitor males fed for 12 weeks on a high-fat diet (HFD) revealed alterations in the expression of many small non-coding RNAs, including piRNAs. F1 animals have reduced birth weight and decreased $\beta$-cell mass. Glucose intolerance is observed exclusively in F1 females. (B) In a piwi-mutant Drosophila model, depletion of piRNAs in the fat body, which has functions equivalent to mammalian liver, results in defects in glucose and lipid metabolism as observed in metabolic disorders such as diabetes. The link between the decline in piRNA expression and the observed metabolic phenotype remains however to be established. (C) The expression profile of piRNAs in rat islet cells changes during postnatal development and $\beta$-cell maturation. Dysregulation of piRNA levels is also observed in the islets of non-obese diabetic Goto-Kakisaki (GK) rats. In vitro experiments mimicking the changes in the level of certain piRNAs observed in GK rats result in defective insulin secretion of healthy rat islets in response to glucose. Depletion of piRNAs secondary to silencing of the PIWI-like genes Piwil2 and Piwil4 in adult islets promotes $\beta$-cell proliferation, which is normally very low in adulthood.

(SNORD33), U34 (SNORD34), and U35a (SNORD 35a)] known to introduce 2'-O-Methylations in target RNAs is increased (Figure 6A) (127). Disruption of the locus ribosomal protein L13a (rpL13a), which encodes for three of these box C/D small nucleolar RNAs (snoRNAs 32a, 33 and 35) from intronic regions, confers resistance to lipotoxicity to an ovarian cell line. The loss of these snoRNAs, rather than the RPL13A protein, is responsible for resistance to oxidative stress and mitochondrial dysfunction secondary to exposure to high lipid concentrations (Figure 6A) (127). The effect of these snoRNAs in propagating oxidative stress in the liver of mice treated with the inflammatory agent Lipopolysaccharide (LPS) has also been demonstrated in vivo (127). Additional findings are consistent with these observations and link this phenotype to a physiopathological context. A mouse model (Rpl13a-snoless mice) in which four snoRNAs-hosting introns (encoding for SNORD32a, -33, -34 and -35) have been specifically deleted without disturbing the expression of the ribosomal protein Rpl13a has been generated (128). The absence of these four snoRNAs leads to a drop in the level of reactive oxygen species (ROS), 
A
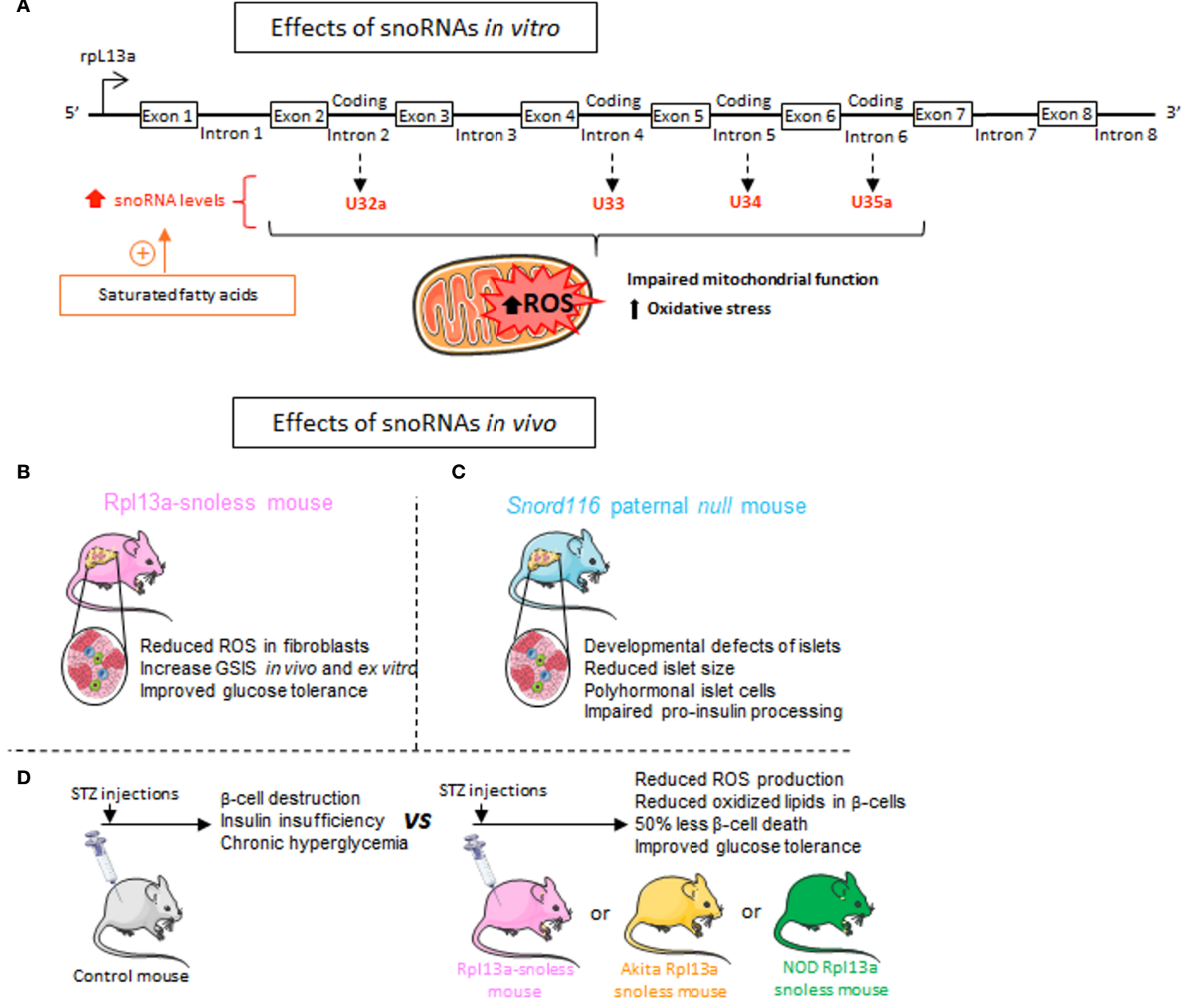

FIGURE 6 | Metabolic effects of snoRNAs. (A) Exposure of Chinese hamster ovarian cells and C2C12 Murine Myoblasts to saturated fatty acids including palmitate, results in an increase in the 4 snoRNAs encoded by the introns of Rlp13a gene. These four snoRNAs are known to induce 2'-O-Methylations of target RNAs and mediate palmitate-induced lipotoxic effects on mitochondrial dysfunction and oxidative stress. (B) Mice invalidated for the 4 snoRNAs U32a (SNORD32a), U33 (SNORD33), U34 (SNORD34), and U35a (SNORD 35a) named Rpl13a-snoless mice, display reduced Reactive Oxygen Species (ROS) production, increased insulin secretion and improved glucose tolerance. (C) Rp/13a-snoless mice treated with the $\beta$-cell death inducer Streptozotocin (STZ) or bred with Ins2C96Y Akita mice or non-obese diabetic (NOD) mice are protected against the development of chronic hyperglycemia, show less oxidative stress and improved glucose tolerance.

(D) Patients with Prader-Willi syndrome (PWS) who develop severe obesity and metabolic disorders carry a loss of paternally expressed genes on chromosome 15 which encodes for SNORD116. To reproduce the genetic background of PWS patients, a paternal Snord116 mouse knockout (Snord116p-/m+) has been generated. Genetic deletion of SNORD116 leads to defects in pancreatic endocrine development along with metabolic disturbances.

resulting in an increase in insulin secretion in response to glucose from pancreatic islets and an improvement in glucose tolerance (Figure 6B) (128). Since ROS have been shown to be involved in diabetes pathogenesis in humans and various animal models, the authors evaluated the resistance of the mice to diabetes development following the administration of low doses of streptozotocin (STZ), an agent that causes oxidative stress and $\beta$-cells death. Upon STZ treatment, Rpl13a-snoless mice displayed improved glucose tolerance compared to control mice. Histological analysis of the pancreas revealed that $\beta$-cells of Rpl13a-snoless mice are protected from STZ-induced accumulation of oxidized lipids that are toxic to insulin-secreting cells and show $50 \%$ less $\beta$ cell death compared to control animals. Similar results were obtained from two other mouse models showing oxidative damage in $\beta$-cells leading to apoptosis and development of diabetes, including Akita mice carrying the Ins2C96Y allele and non-obese diabetic mice (NOD). This study provides evidence that Rpl13a snoRNAs contribute to the hyperglycemia observed in three mouse diabetes models presenting an inflammatory context associated with $\beta$-cell demise (Figure 6C) (128).

Being mainly known to guide post-transcriptional modifications of ribosomal and small nuclear RNAs, snoRNAs resonate as potentially vital factors in the drastic reshaping of the transcriptional and proteomic landscape associated with metabolic diseases $(7,129)$. Various independent studies revealed a contribution of snoRNAs to the control of food 
intake and to body weight regulation in patients suffering from the neurodevelopmental disorder called Prader-Willi syndrome (PWS). PWS is a multifactorial pathology leading to morbid obesity and metabolic syndrome (130). The units coding for the orphan snoRNAs SNORD115 and SNORD116 reside within an intronic region of chromosome 15 whose deletion results in the development of PWS $(131,132)$. Concomitant overexpression of these two snoRNAs in HEK293T cells induces changes in the level of more than twenty transcripts corresponding to genes whose expression is also disrupted in the brains of subjects with PWS (133). The mechanisms underlying this effect are not yet known and it remains to be determined whether SNORD115 and SNORD116 directly affect the stability of the identified mRNAs or act via an intermediate trans-acting factor. In vivo, mice invalidated for SNORD116 display major metabolic alterations, including a defect in the development of the endocrine pancreas (134) and in proinsulin processing (Figure 6D) (135). The islets of these mice are smaller with an increase in the number of $\delta$ cells secreting the insulin antagonist hormone somatostatin and a decrease in glucagon-secreting $\alpha$-cells. Moreover, markers of $\beta$ cell differentiation and function such as Ins1, Ins2, Pdx1, Nkx6-1, and Pax6 are reduced (134).

Alongside, both PWS and diabetic patients have alterations in circadian rhythms defined as a misalignment between the endogenous clock system and behavioral circadian cycles (for example, sleep-wake and fasting-feeding cycles) (136, 137). Several studies have investigated the rhythmic expression of snoRNAs in various organisms and tissues $(79,138,139)$. In mice, genetic deletion within the SNORD116/Snord116 region affects sleep physiology and suggests a role for the small nucleolar ribonucleic acid-116 (SNORD116) in sleep alterations involving the rapid eye movement (REM) phase which is perturbed in most patients with PWS $(140,141)$. In light of these data, snoRNAs could be key regulators of the molecular pathways contributing to rhythmic transcriptome and proteome defects associated with diabetes. Taken together, these findings implicate snoRNAs in the development of metabolic disorders and pave the way for the discovery of new factors causing chronic multifactorial endocrine diseases.

Not only the expression of snoRNAs is dynamic in response to various exogenous stimuli, but also their location is sensitive to environmental factors. The release of snoRNAs into the bloodstream by macrophages via extracellular vesicles results in an inflammatory context in mouse models and human subjects (84). The authors of this study showed using parabiosis experiments that snoRNAs released into the circulation are capable of inducing 2'-O-methylations of RNAs in various peripheral tissues including enterocytes. How tissues are specifically targeted by vesicles carrying snoRNAs and whether these small RNAs significantly contribute to the immune response induced in recipient cells remains to date unknown.

\section{Identified tRFs and Diabetes}

Intergenerational inheritance of metabolic disorders and $\beta$-cell dysfunction are established (142-144). In recent years, paternal metabolic challenges were shown to be correlated with alterations in sperm tRFs in humans, mice, and rats $(111,120$, $145,146)$. Importantly, isolation of sperm tRFs from mice fed a high fat diet and injection of these tRFs into healthy zygotes was sufficient to dysregulate islet transcriptome and trigger an obesogenic phenotype in F1 mice (Figure 7A) (145). In line with this observation, another study illustrated that maternal high fat diet induces an obesogenic phenotype in F1, and injection of tRFs isolated from F1 into healthy zygotes reproduced the phenotype observed in F1 (147). Altogether, these studies underline the contribution of tRFs to intergenerational inheritance of diet-induced metabolic disorders. Mechanistically, high fat diet altered the methylation status and stability of tRFs which in turn repressed a subset of metabolic genes at an embryonic stage, in a miRNA-like fashion (145). Accordingly, tiRNA-5 ${ }^{\text {GluCTC }}$, a diet-regulated sperm tRF, was enriched upon Ago2 immunoprecipitation (148).

While the impact of sperm tRFs on the offspring's metabolism is rapidly unraveling, the tRF landscape and function in $\beta$-cells remain largely elusive. The only study on tRF function in $\beta$-cells was recently published in the context of monogenic mutations in TRMT10A gene encoding for a tRNA methyltransferase (149). This mutation causes young onset diabetes and microcephaly (150). In $\beta$-cells, TRMT10A deficiency was shown to cause oxidative stress and trigger apoptosis. However, the mechanism underlying the $\beta$-cell apoptosis was unknown. In the study cited above (149), glutamine tRNAs were shown to be hypomethylated in the absence of TRMT10A, leading to increased tRNA fragmentation and accumulation of tRF-5s. Interestingly, transfecting the EndoC-H1 human $\beta$-cell line with glutamine tRF-5 mimics increased $\beta$-cell apoptosis. Conversely, inhibition of the fragment in TRMT10A deficient $\beta$-cells decreased apoptosis, suggesting that $\beta$-cell death observed in TRMT10A mutations may be attributed to this tRF (Figure 7B). While the exact mechanism of tRF-induced $\beta$-cell apoptosis is unknown, it can be speculated that the tRF is interacting with Cytochrome $c$ to regulate this process, as reported in other models (118).

Since $\beta$-cell death is a key event in T1D development, future studies in T1D models, such as NOD mice, may help elucidate the involvement of tRFs in this form of the disease.

\section{CONCLUSION AND FUTURE PERSPECTIVES}

The last few years have witnessed tremendous advancements in the understanding of the physiological role of different classes of ncRNAs and of their involvement in the etiology of multifactorial pathologies such as diabetes. Among them, the newly identified piRNAs, snoRNAs and tRFs are emerging as important regulators of signaling pathways activated or affected during the development of diabetes, thus placing them as potential therapeutic targets for the treatment of this metabolic disease. The capacity of ncRNAs to control the stability of genomic elements or transcripts but also to modulate several 
A

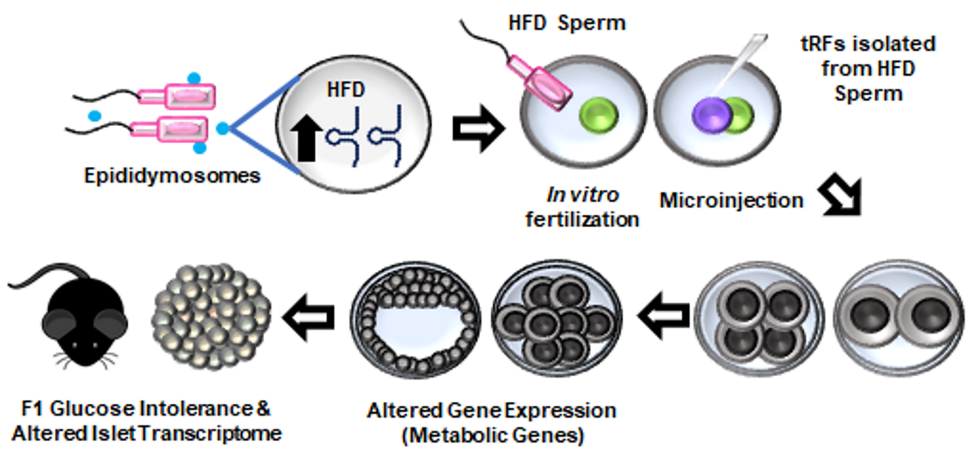

B

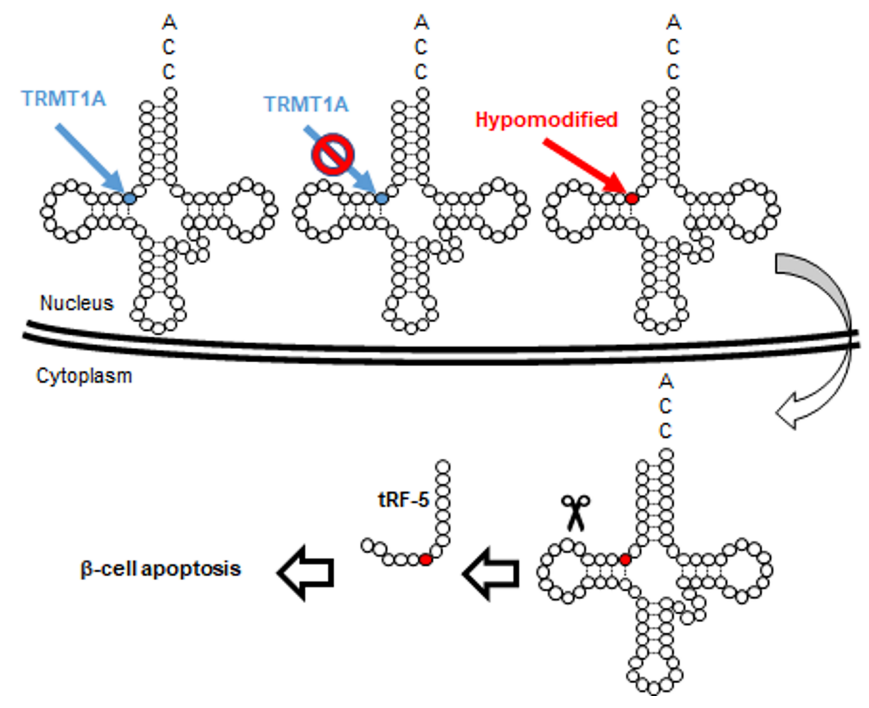

FIGURE 7 | Roles of tRFs in metabolic disorders and $\beta$-cell dysfunction. (A) Paternal high fat diet (HFD) increases the abundance of tiRNA-5s that are packaged inside epididymis-derived exosomes (epididymosomes). Epididymosomes fuse with the sperm and transfer these fragments. When normal zygotes are fertilized with HFD sperm or microinjected with tRFs isolated from HFD sperm, expression of metabolic genes in eight-cell and blastocyst-stage embryos is drastically altered. The resulting offspring exhibit abnormal metabolism at adulthood, including glucose intolerance and alterations in pancreatic islet transcriptome. A similar metabolic function of tRFs is observed upon a paternal low protein diet. (B) TRMT10A deficiency is associated with hypomethylation of guanosine residues at position 9 of certain tRNAs. Hypomethylated tRNAs are transported to the cytoplasm and fragmented. tRF-5s generated from such fragmentations lead to $\beta$-cell apoptosis.

downstream pathways can drastically impact the molecular and functional landscape of the cells, justifying efforts to develop drugs specifically targeting these molecules. Pre-clinical studies involving the use of synthetic miRNA-based therapeutic molecules have already shown remarkable and very promising results in term of ability to reach and penetrate cells (hepatocytes, tumor cells, etc.) and to accomplish relevant regulatory activities (151). Early-phase human clinical trials that target miRNAs raise a lot of hope on the feasibility of applying similar strategies to modulate also the level or the function of other classes of small ncRNAs such as piRNAs, snoRNAs and tRFs in diabetes therapy. The strategy employed is to modulate ncRNA levels and/or activity in either insulin-secreting $\beta$-cells or in other cells implicated in the pathogenesis of diabetes (other islet cell types, insulin target tissues, central nervous system) (151). For over-active ncRNAs, the approach consists in using antisense oligonucleotides or CRISPR/Cas9 in order to attenuate or block the effects of the selected ncRNA. For palliating the absence or the inhibitory activity of ncRNAs, a replacement therapy can be envisaged via synthetic oligonucleotides mimicking the ncRNA sequence. The injection of "mimic" or "inhibitor" molecules to the targeted tissue can be mediated by protective delivery methods such as lipid-based nanoparticles, exosomes, or polymer-based delivery systems (152-155). Some ncRNAs are specifically expressed or selectively up or down-regulated in a particular cell type depending on the pathophysiological context. Since each ncRNA can play potentially different roles according to the host cell, the real challenge will be to successfully target a specific cell type and thus minimize the side effects that could be caused by ubiquitous modulation of the ncRNA.

We are only beginning to appreciate the role of piRNAs, snoRNAs and tRFs in pancreatic $\beta$-cells and in metabolic tissues and their possible involvement in different forms of diabetes. A better understanding of the mode of action and of the 
contribution of these small ncRNAs to the etiology of diabetes will help identifying potential targets for the development of new pharmaceutical principles to prevent or treat this metabolic disorder. The design of drugs to modulate the level or the activity of piRNAs, snoRNAs or tRFs will certainly take advantage of the knowledge gathered from the growing interest for siRNA- or miRNA-based therapeutic approaches, a field of intense investigation. Thus, there is hope that if relevant piRNAs, snoRNAs or tRFs targets will be identified, the development of therapeutic approaches to modulate the activities of these small ncRNAs will be greatly accelerated.

\section{REFERENCES}

1. Lander ES, Linton LM, Birren B, Nusbaum C, Zody MC, Baldwin J, et al. Initial Sequencing and Analysis of the Human Genome. Nature (2001) 409:860-921. doi: 10.1038/35057062

2. Venter JC, Adams MD, Myers EW, Li PW, Mural RJ, Sutton GG, et al. The Sequence of the Human Genome. Science (2001) 291:1304-51. doi: 10.1126/ science. 1058040

3. Consortium EP. An Integrated Encyclopedia of DNA Elements in the Human Genome. Nature (2012) 489:57-74. doi: 10.1038/nature11247

4. Santosh B, Varshney A, Yadava PK. Non-Coding RNAs: Biological Functions and Applications. Cell Biochem Funct (2015) 33:14-22. doi: 10.1002/cbf.3079

5. Bhaskaran M, Mohan M. MicroRNAs: History, Biogenesis, and Their Evolving Role in Animal Development and Disease. Vet Pathol (2014) 51:759-74. doi: 10.1177/0300985813502820

6. Kloosterman WP, Plasterk RHA. The Diverse Functions of MicroRNAs in Animal Development and Disease. Dev Cell (2006) 11:441-50. doi: 10.1016/ j.devcel.2006.09.009

7. Guay C, Jacovetti C, Bayazit MB, Brozzi F, Rodriguez-Trejo A, Wu K, et al. Roles of Noncoding RNAs in Islet Biology. Compr Physiol (2020) 10:893932. doi: 10.1002/cphy.c190032

8. DiMeglio LA, Evans-Molina C, Oram RA. Type 1 Diabetes. Lancet (2018) 391:2449-62. doi: 10.1016/S0140-6736(18)31320-5

9. Himanshu D, Ali W, Wamique M. Type 2 Diabetes Mellitus: Pathogenesis and Genetic Diagnosis. J Diabetes Metab Disord (2020) 19:1959-66. doi: 10.1007/s40200-020-00641-x

10. Czech B, Munafo M, Ciabrelli F, Eastwood EL, Fabry MH, Kneuss E, et al. piRNA-Guided Genome Defense: From Biogenesis to Silencing. Annu Rev Genet (2018) 52:131-57. doi: 10.1146/annurev-genet-120417-031441

11. Ozata DM, Yu TX, Mou HW, Gainetdinov I, Colpan C, Cecchini K, et al. Evolutionarily Conserved Pachytene piRNA Loci are Highly Divergent Among Modern Humans. Nat Ecol Evol (2020) 4:156-+. doi: 10.1038/ s41559-019-1065-1

12. Henaoui IS, Jacovetti C, Mollet IG, Guay C, Sobel J, Eliasson L, et al. PIWIInteracting RNAs as Novel Regulators of Pancreatic Beta Cell Function. Diabetologia (2017) 60:1977-86. doi: 10.1007/s00125-017-4368-2

13. Liu YM, Dou M, Song XX, Dong YH, Liu S, Liu HR, et al. The Emerging Role of the piRNA/piwi Complex in Cancer. Mol Cancer (2019) 18(1):123. doi: 10.1186/s12943-019-1052-9

14. Wu X, Pan YT, Fang Y, Zhang JX, Xie MY, Yang FM, et al. The Biogenesis and Functions of piRNAs in Human Diseases. Mol Ther Nucl Acids (2020) 21:108-20. doi: 10.1016/j.omtn.2020.05.023

15. Lim RSM, Kai T. A Piece of the Pi(E): The Diverse Roles of Animal piRNAs and Their PIWI Partners. Semin Cell Dev Biol (2015) 47-48:17-31. doi: 10.1016/j.semcdb.2015.10.025

16. Czech B, Hannon GJ. One Loop to Rule Them All: The Ping-Pong Cycle and piRNA-Guided Silencing. Trends Biochem Sci (2016) 41:324-37. doi: 10.1016/j.tibs.2015.12.008

17. Nishibu T, Hayashida Y, Tani S, Kurono S, Kojima-Kita K, Ukekawa R, et al. Identification of MIWI-associated Poly(a) RNAs by Immunoprecipitation With an anti-MIWI Monoclonal Antibody. Biosci Trends (2012) 6:248-61. doi: 10.5582/bst.2012.v6.5.248

\section{AUTHOR CONTRIBUTIONS}

$\mathrm{CJ}, \mathrm{MB}$, and RR searched the literature and wrote the article. All authors contributed to the article and approved the submitted version.

\section{FUNDING}

The authors are supported by a grant from the Swiss National Science Foundation (310030_188447).

18. Barckmann B, Dufourt J, Simonelig M. iCLIP of the PIWI Protein Aubergine in Drosophila Embryos. Methods Mol Biol (2018) 1720:89-110. doi: 10.1007/ 978-1-4939-7540-2_7

19. Zhang Y, Wang XH, Kang L. A K-Mer Scheme to Predict piRNAs and Characterize Locust Pirnas. Bioinformatics (2011) 27:771-6. doi: 10.1093/ bioinformatics/btr016

20. Li DF, Luo LQ, Zhang W, Liu F, Luo F. A Genetic Algorithm-Based Weighted Ensemble Method for Predicting Transposon-Derived Pirnas. BMC Bioinf (2016) 17(1):329. doi: 10.1186/s12859-016-1206-3

21. Wang K, Liang C, Liu JD, Xiao HM, Huang SQ, Xu JH, et al. Prediction of piRNAs Using Transposon Interaction and a Support Vector Machine. BMC Bioinf (2014) 15:419. doi: 10.1186/s12859-014-0419-6

22. Brayet J, Zehraoui F, Jeanson-Leh L, Israeli D, Tahi F. Towards a piRNA Prediction Using Multiple Kernel Fusion and Support Vector Machine. Bioinformatics (2014) 30:I364-70. doi: 10.1093/bioinformatics/btu441

23. Wang K, Hoeksema J, Liang C. piRNN: Deep Learning Algorithm for piRNA Prediction. Peerj (2018) 6:e5429. doi: 10.7717/peerj.5429

24. Kufel J, Grzechnik P. Small Nucleolar Rnas Tell a Different Tale. Trends Genet (2019) 35:104-17. doi: 10.1016/j.tig.2018.11.005

25. Ojha S, Malla S, Lyons SM. Snornps: Functions in Ribosome Biogenesis. Biomolecules (2020) 10(5):783. doi: 10.3390/biom 10050783

26. Boisvert FM, van Koningsbruggen S, Navascues J, Lamond AI. The Multifunctional Nucleolus. Nat Rev Mol Cell Biol (2007) 8:574-85. doi: $10.1038 / \mathrm{nrm} 2184$

27. Iarovaia OV, Minina EP, Sheval EV, Onichtchouk D, Dokudovskaya S, Razin SV, et al. Nucleolus: A Central Hub for Nuclear Functions. Trends Cell Biol (2019) 29:647-59. doi: 10.1016/j.tcb.2019.04.003

28. Sloan KE, Warda AS, Sharma S, Entian KD, Lafontaine DLJ, Bohnsack MT. Tuning the Ribosome: The Influence of rRNA Modification on Eukaryotic Ribosome Biogenesis and Function. RNA Biol (2017) 14:1138-52. doi: 10.1080/15476286.2016.1259781

29. Dieci G, Preti M, Montanini B. Eukaryotic snoRNAs: A Paradigm for Gene Expression Flexibility. Genomics (2009) 94:83-8. doi: 10.1016/ j.ygeno.2009.05.002

30. Lyons SM, Fay MM, Ivanov P. The Role of RNA Modifications in the Regulation of tRNA Cleavage. FEBS Lett (2018) 592:2828-44. doi: 10.1002/ 1873-3468.13205

31. Kiss T. Biogenesis of Small Nuclear Rnps. J Cell Sci (2004) 117:5949-51. doi: $10.1242 /$ jcs.01487

32. Darzacq X, Jady BE, Verheggen C, Kiss AM, Bertrand E, Kiss T. Cajal BodySpecific Small Nuclear RNAs: A Novel Class of 2 '-O-Methylation and Pseudouridylation Guide RNAs. EMBO J (2002) 21:2746-56. doi: 10.1093/ emboj/21.11.2746

33. Matera AG, Terns RM, Terns MP. Non-Coding RNAs: Lessons From the Small Nuclear and Small Nucleolar RNAs. Nat Rev Mol Cell Biol (2007) 8:209-20. doi: 10.1038/nrm2124

34. Mleczko AM, Bakowska-Zywicka K. When Small RNAs Become Smaller: Emerging Functions of snoRNAs and Their Derivatives. Acta Biochim Pol (2016) 63:601-7. doi: 10.18388/abp.2016_1330

35. Lemay JF, D'Amours A, Lemieux C, Lackner DH, St-Sauveur VG, Bahler J, et al. The Nuclear Poly(a)-Binding Protein Interacts With the Exosome to Promote Synthesis of Noncoding Small Nucleolar RNAs. Mol Cell (2010) 37:34-45. doi: 10.1016/j.molcel.2009.12.019 
36. Tudek A, Lloret-Llinares M, Jensen TH. The Multitasking Polya Tail: Nuclear RNA Maturation, Degradation and Export. Philos Trans $R$ Soc Lond B Biol Sci (2018) 373(1762):20180169. doi: 10.1098/rstb.2018.0169

37. Massenet S, Bertrand E, Verheggen C. Assembly and Trafficking of Box C/D and H/ACA SnoRNPs. RNA Biol (2017) 14:680-92. doi: 10.1080/ 15476286.2016 .1243646

38. Bouchard-Bourelle P, Desjardins-Henri C, Mathurin-St-Pierre D, Deschamps-Francoeur G, Fafard-Couture E, Garant JM, et al. snoDB: An Interactive Database of Human snoRNA Sequences, Abundance and Interactions. Nucleic Acids Res (2020) 48:D220-5. doi: 10.1093/nar/gkz884

39. Gardner PP, Bateman A, Poole AM. SnoPatrol: How Many snoRNA Genes are There? J Biol (2010) 9:4. doi: 10.1186/jbiol211

40. Boivin V, Reulet G, Boisvert O, Couture S, Elela SA, Scott MS. Reducing the Structure Bias of RNA-Seq Reveals a Large Number of non-Annotated nonCoding RNA. Nucleic Acids Res (2020) 48:2271-86. doi: 10.1093/nar/ gkaa028

41. Ma YJ, Dissen GA, Rage F, Ojeda SR. Rnase Protection Assay. Methods (1996) 10:273-8. doi: 10.1006/meth.1996.0102

42. Hubbard TJP, Aken BL, Ayling S, Ballester B, Beal K, Bragin E, et al. Ensembl 2009. Nucleic Acids Res (2009) 37:D690-7. doi: 10.1093/nar/gkn828

43. Jorjani H, Kehr S, Jedlinski DJ, Gumienny R, Hertel J, Stadler PF, et al. An Updated Human Snornaome. Nucleic Acids Res (2016) 44:5068-82. doi: 10.1093/nar/gkw386

44. Lykke-Andersen S, Chen Y, Ardal BR, Lilje B, Waage J, Sandelin A, et al. Human Nonsense-Mediated RNA Decay Initiates Widely by Endonucleolysis and Targets snoRNA Host Genes. Genes Dev (2014) 28:2498-517. doi: 10.1101/gad.246538.114

45. Penzo M, Clima R, Trere D, Montanaro L. Separated Siamese Twins: Intronic Small Nucleolar Rnas and Matched Host Genes may be Altered in Conjunction or Separately in Multiple Cancer Types. Cells (2020) 9 (2):387. doi: 10.3390/cells9020387

46. Warner WA, Spencer DH, Trissal M, White BS, Helton N, Ley TJ, et al. Expression Profiling of snoRNAs in Normal Hematopoiesis and AML. Blood $A d v$ (2018) 2:151-63. doi: 10.1182/bloodadvances.2017006668

47. Abbott JA, Francklyn CS, Robey-Bond SM. Transfer RNA and Human Disease. Front Genet (2014) 5:158. doi: 10.3389/fgene.2014.00158

48. Pace B, Peterson RL, Pace NR. Formation of All Stable RNA Species in Escherichia-Coli by Posttranscriptional Modification. P Natl Acad Sci USA (1970) 65:1097-+. doi: 10.1073/pnas.65.4.1097

49. Lant JT, Berg MD, Heinemann IU, Brandl CJ, O’Donoghue P. Pathways to Disease From Natural Variations in Human Cytoplasmic tRNAs. J Biol Chem (2019) 294:5294-308. doi: 10.1074/jbc.REV118.002982

50. Salinas-Giege T, Giege R, Giege P. Trna Biology in Mitochondria. Int J Mol Sci (2015) 16:4518-59. doi: 10.3390/ijms16034518

51. Pan T. Modifications and Functional Genomics of Human Transfer RNA. Cell Res (2018) 28:395-404. doi: 10.1038/s41422-018-0013-y

52. Schimmel P. The Emerging Complexity of the tRNA World: Mammalian tRNAs Beyond Protein Synthesis. Nat Rev Mol Cell Bio (2018) 19:45-58. doi: 10.1038/nrm.2017.77

53. Goncalves KA, Silberstein L, Li SP, Severe N, Hu MFG, Yang HL, et al. Angiogenin Promotes Hematopoietic Regeneration by Dichotomously Regulating Quiescence of Stem and Progenitor Cells. Cell (2016) 166:894906. doi: 10.1016/j.cell.2016.06.042

54. Huh D, Passarelli MC, Gao J, Dusmatova SN, Goin C, Fish L, et al. A StressInduced tyrosine-tRNA Depletion Response Mediates Codon-Based Translational Repression and Growth Suppression. EMBO J (2020) 40(2): e106696. doi: 10.15252/embj.2020106696

55. Tao EW, Cheng WY, Li WL, Yu J, Gao QY. Tirnas: A Novel Class of Small Noncoding RNAs That Helps Cells Respond to Stressors and Plays Roles in Cancer Progression. J Cell Physiol (2020) 235:683-90. doi: 10.1002/ jcp. 29057

56. Torres AG, Reina O, Attolini CSO, de Pouplana LR. Differential Expression of Human tRNA Genes Drives the Abundance of tRNA-derived Fragments. P Natl Acad Sci USA (2019) 116:8451-6. doi: 10.1073/pnas.1821120116

57. Yang JY, Deng XY, Li YS, Ma XC, Feng JX, Yu B, et al. Structure of Schlafen13 Reveals a New Class of tRNA/rRNA- Targeting RNase Engaged in Translational Control. Nat Commun (2018) 9. doi: 10.1038/s41467-01803544-x
58. Chan PP, Lowe TM. GtRNAdb 2.0: An Expanded Database of Transfer RNA Genes Identified in Complete and Draft Genomes. Nucleic Acids Res (2016) 44:D184-9. doi: 10.1093/nar/gkv1309

59. Guzzi N, Ciesla M, Ngoc PCT, Lang S, Arora S, Dimitriou M, et al. Pseudouridylation of tRNA-Derived Fragments Steers Translational Control in Stem Cells. Cell (2018) 173:1204-+. doi: 10.1016/ j.cell.2018.03.008

60. Cozen AE, Quartley E, Holmes AD, Hrabeta-Robinson E, Phizicky EM, Lowe TM. ARM-Seq: AlkB-facilitated RNA Methylation Sequencing Reveals a Complex Landscape of Modified tRNA Fragments. Nat Methods (2015) 12:879-+. doi: 10.1038/nmeth.3508

61. Zheng GQ, Qin YD, Clark WC, Dai Q, Yi CQ, He C, et al. Efficient and Quantitative High-Throughput tRNA Sequencing. Nat Methods (2015) 12:835-+. doi: 10.1038/nmeth.3478

62. Zheng LL, Xu WL, Liu S, Sun WJ, Li JH, Wu J, et al. Trf2cancer: A Web Server to Detect tRNA-derived Small RNA Fragments (tRFs) and Their Expression in Multiple Cancers. Nucleic Acids Res (2016) 44:W185-93. doi: 10.1093/nar/gkw414

63. Loher P, Telonis AG, Rigoutsos I. Mintmap: Fast and Exhaustive Profiling of Nuclear and Mitochondrial tRNA Fragments From Short RNA-seq Data. Sci Rep Uk (2017) 7:1-20. doi: 10.1038/srep41184

64. Liu Q, Ding C, Lang X, Guo G, Chen J, Su X. Small Noncoding RNA Discovery and Profiling With sRNAtools Based on High-Throughput Sequencing. Brief Bioinform (2021) 22:463-73. doi: 10.1093/bib/bbz151

65. Ozata DM, Gainetdinov I, Zoch A, O'Carroll D, Zamore PD. PIWIInteracting RNAs: Small RNAs With Big Functions. Nat Rev Genet (2019) 20:89-108. doi: 10.1038/s41576-018-0073-3

66. Sarkar A, Volff JN, Vaury C. piRNAs and Their Diverse Roles: A Transposable Element-Driven Tactic for Gene Regulation? FASEB J (2017) 31:436-46. doi: 10.1096/fj.201600637RR

67. Ernst C, Odom DT, Kutter C. The Emergence of piRNAs Against Transposon Invasion to Preserve Mammalian Genome Integrity. Nat Commun (2017) 8(1):1411. doi: 10.1038/s41467-017-01049-7

68. Rojas-Rios P, Simonelig M. piRNAs and PIWI Proteins: Regulators of Gene Expression in Development and Stem. Development (2018) 145(17): dev161786. doi: 10.1242/dev.161786

69. Iwasaki YW, Siomi MC, Siomi H, PIWI-Interacting RNA. Its Biogenesis and Functions. Annu Rev Biochem (2015) 84:405-33. doi: 10.1146/annurevbiochem-060614-034258

70. Ophinni Y, Palatini U, Hayashi Y, Parrish NF. piRNA-Guided CRISPR-like Immunity in Eukaryotes. Trends Immunol (2019) 40:998-1010. doi: 10.1016/j.it.2019.09.003

71. Suzuki Y, Baidaliuk A, Miesen P, Frangeul L, Crist AB, Merkling SH, et al. Non-Retroviral Endogenous Viral Element Limits Cognate Virus Replication in Aedes Aegypti Ovaries. Curr Biol (2020) 30:3495-+. doi: 10.1016/j.cub.2020.06.057

72. Zhang DL, Tu SK, Stubna M, Wu WS, Huang WC, Weng ZP, et al. The piRNA Targeting Rules and the Resistance to piRNA Silencing in Endogenous Genes. Science (2018) 359:587-91. doi: 10.1126/ science.aao 2840

73. Shen EZ, Chen H, Ozturk AR, Tu SK, Shirayama M, Tang W, et al. Identification of Pirna Binding Sites Reveals the Argonaute Regulatory Landscape of the C-elegans Germline. Cell (2018) 172:937-+. doi: 10.1016/j.cell.2018.02.002

74. Wu WS, Brown JS, Chen TT, Chu YH, Huang WC, Tu SK, et al. piRTarBase: A Database of piRNA Targeting Sites and Their Roles in Gene Regulation. Nucleic Acids Res (2019) 47:D181-7. doi: 10.1093/nar/gky956

75. Wu WS, Huang WC, Brown JS, Zhang DL, Song XY, Chen H, et al. pirScan: A Webserver to Predict piRNA Targeting Sites and to Avoid Transgene Silencing in C. elegans. Nucleic Acids Res (2018) 46:W43-8. doi: 10.1093/ nar/gky277

76. Bratkovic T, Bozic J, Rogelj B. Functional Diversity of Small Nucleolar RNAs. Nucleic Acids Res (2020) 48:1627-51. doi: 10.1093/nar/gkz1140

77. Watkins NJ, Bohnsack MT. The Box C/D and H/ACA snoRNPs: Key Players in the Modification, Processing and the Dynamic Folding of Ribosomal RNA. Wires RNA (2012) 3:397-414. doi: 10.1002/wrna.117

78. Karijolich J, Yu YT. Spliceosomal snRNA Modifications and Their Function. RNA Biol (2010) 7:192-204. doi: 10.4161/rna.7.2.11207 
79. Aitken S, Semple CA. The Circadian Dynamics of Small Nucleolar RNA in the Mouse Liver. J R Soc Interface (2017) 14(130):20170034. doi: 10.1101/ 102533

80. Zhong FD, Zhou N, Wu K, Guo YB, Tan WP, Zhang H, et al. A SnoRNAderived piRNA Interacts With Human Interleukin-4 pre-mRNA and Induces its Decay in Nuclear Exosomes. Nucleic Acids Res (2015) 43:10474-91. doi: 10.1093/nar/gkv954

81. Bergeron D, Fafard-Couture E, Scott MS. Small Nucleolar RNAs: Continuing Identification of Novel Members and Increasing Diversity of Their Molecular Mechanisms of Action. Biochem Soc T (2020) 48:645-56. doi: 10.1042/BST20191046

82. Holley CL, Li MW, Scruggs BS, Matkovich SJ, Ory DS, Schaffer JE. Cytosolic Accumulation of Small Nucleolar RNAs (SnoRNAS) Is Dynamically Regulated by NADPH Oxidase. J Biol Chem (2015) 290:11741-8. doi: 10.1074/jbc.M115.637413

83. Li MW, Sletten AC, Lee J, Pyles KD, Matkovich SJ, Ory DS, et al. Nuclear Export Factor 3 Regulates Localization of Small Nucleolar Rnas. J Biol Chem (2017) 292:20228-39. doi: 10.1074/jbc.M117.818146

84. Rimer JM, Lee J, Holley CL, Crowder RJ, Chen DL, Hanson PI, et al. LongRange Function of Secreted Small Nucleolar RNAs That Direct 2 '-OMethylation. J Biol Chem (2018) 293:13284-96. doi: 10.1074/ jbc.RA118.003410

85. Yang JH, Zhang XC, Huang ZP, Zhou H, Huang MB, Zhang S, et al. snoSeeker: An Advanced Computational Package for Screening of Guide and Orphan snoRNA Genes in the Human Genome. Nucleic Acids Res (2006) 34:5112-23. doi: 10.1093/nar/gkl672

86. Yin QF, Yang L, Zhang Y, Xiang JF, Wu YW, Carmichael GG, et al. Long Noncoding Rnas With snoRNA Ends. Mol Cell (2012) 48:219-30. doi: 10.1016/j.molcel.2012.07.033

87. Swiatowy W, Jagodzinski PP. Molecules Derived From tRNA and SnoRNA: Entering the Degradome Pool. BioMed Pharmacother (2018) 108:36-42. doi: 10.1016/j.biopha.2018.09.017

88. Bai BY, Yegnasubramanian S, Wheelan SJ, Laiho M. RNA-Seq of the Nucleolus Reveals Abundant Snord44-Derived Small RNAs. PloS One (2014) 9(9):e107519. doi: 10.1371/journal.pone.0107519

89. Brameier M, Herwig A, Reinhardt R, Walter L, Gruber J. Human Box C/D snoRNAs With miRNA Like Functions: Expanding the Range of Regulatory Rnas. Nucleic Acids Res (2011) 39:675-86. doi: 10.1093/nar/gkq776

90. Burroughs AM, Ando Y, de Hoon MJL, Tomaru Y, Suzuki H, Hayashizaki Y, et al. Deep-Sequencing of Human Argonaute-Associated Small RNAs Provides Insight Into miRNA Sorting and Reveals Argonaute Association With RNA Fragments of Diverse Origin. RNA Biol (2011) 8:158-77. doi: 10.4161/rna.8.1.14300

91. Ender C, Krek A, Friedlander MR, Beitzinger M, Weinmann L, Chen W, et al. A Human snoRNA With MicroRNA-Like Functions. Mol Cell (2008) 32:519-28. doi: 10.1016/j.molcel.2008.10.017

92. Kishore S, Khanna A, Zhang ZY, Hui JY, Balwierz PJ, Stefan M, et al. The Snorna MBII-52 (SNORD 115) is Processed Into Smaller RNAs and Regulates Alternative Splicing. Hum Mol Genet (2010) 19:1153-64. doi: $10.1093 / \mathrm{hmg} / \mathrm{ddp} 585$

93. Mleczko AM, Machtel P, Walkowiak M, Wasilewska A, Pietras PJ, Bakowska-Zywicka K. Levels of sdRNAs in Cytoplasm and Their Association With Ribosomes are Dependent Upon Stress Conditions But Independent From snoRNA Expression. Sci Rep Uk (2019) 9(1):18397. doi: 10.1038/s41598-019-54924-2

94. Gumienny R, Jedlinski DJ, Schmidt A, Gypas F, Martin G, Vina-Vilaseca A, et al. High-Throughput Identification of C/D Box snoRNA Targets With CLIP and Ribometh-Seq. Nucleic Acids Res (2017) 45:2341-53. doi: 10.1101/ 037259

95. Marchand V, Blanloeil-Oillo F, Helm M, Motorin Y. Illumina-Based RiboMethSeq Approach for Mapping of 2'-O-Me Residues in RNA. Nucleic Acids Res (2016) 44(16):e135. doi: 10.1093/nar/gkw547

96. Lin CY, Miles WO, Beyond CLIP. Advances and Opportunities to Measure RBP-RNA and RNA-RNA Interactions. Nucleic Acids Res (2019) 47:5490501. doi: 10.1093/nar/gkz295

97. Ule J, Hwang HW, Darnell RB. The Future of Cross-Linking and Immunoprecipitation (Clip). Csh Perspect Biol (2018) 10(8):a032243. doi: 10.1101/cshperspect.a032243
98. Kudla G, Granneman S, Hahn D, Beggs JD, Tollervey D. Cross-Linking, Ligation, and Sequencing of Hybrids Reveals RNA-RNA Interactions in Yeast. P Natl Acad Sci USA (2011) 108:10010-5. doi: 10.1073/pnas.1017386108

99. Kishore S, Gruber AR, Jedlinski DJ, Syed AP, Jorjani H, Zavolan M. Insights Into snoRNA Biogenesis and Processing From PAR-CLIP of snoRNA Core Proteins and Small RNA Sequencing. Genome Biol (2013) 14:R45. doi: 10.1186/gb-2013-14-5-r45

100. Sugimoto Y, Chakrabarti AM, Luscombe NM, Ule J. Using hiCLIP to Identify RNA Duplexes That Interact With a Specific RNA-binding Protein. Nat Protoc (2017) 12:611-37. doi: 10.1038/nprot.2016.188

101. Sharma E, Sterne-Weiler T, O'Hanlon D, Blencowe BJ. Global Mapping of Human Rna-RNA Interactions. Mol Cell (2016) 62:618-26. doi: 10.1016/ j.molcel.2016.04.030

102. Lu ZP, Zhang QC, Lee B, Flynn RA, Smith MA, Robinson JT, et al. Rna Duplex Map in Living Cells Reveals Higher-Order Transcriptome Structure. Cell (2016) 165:1267-79. doi: 10.1016/j.cell.2016.04.028

103. Aw JGA, Shen Y, Wilm A, Sun M, Lim XN, Boon KL, et al. In Vivo Mapping of Eukaryotic Rna Interactomes Reveals Principles of Higher-Order Organization and Regulation. Mol Cell (2016) 62:603-17. doi: 10.1016/ j.molcel.2016.04.028

104. Ziv O, Gabryelska MM, Lun ATL, Gebert LFR, Sheu-Gruttadauria J, Meredith LW, et al. COMRADES Determines In Vivo RNA Structures and Interactions. Nat Methods (2018) 15:785-+. doi: 10.1038/s41592-0180121-0

105. Helwak A, Kudla G, Dudnakova T, Tollervey D. Mapping the Human Mirna Interactome by CLASH Reveals Frequent Noncanonical Binding. Cell (2013) 153:654-65. doi: 10.1016/j.cell.2013.03.043

106. Dupuis-Sandoval F, Poirier M, Scott MS. The Emerging Landscape of Small Nucleolar RNAs in Cell Biology. Wires RNA (2015) 6:381-97. doi: 10.1002/ wrna. 1284

107. Cho H, Lee W, Kim GW, Lee SH, Moon JS, Kim M, et al. Regulation of La/ SSB-dependent Viral Gene Expression by pre-tRNA 3 'Trailer-Derived tRNA Fragments. Nucleic Acids Res (2019) 47:9888-901. doi: 10.1093/nar/ gkz732

108. Giudice G, Sanchez-Cabo F, Torroja C, Lara-Pezzi E. AttRACT-a Database of RNA-binding Proteins and Associated Motifs. Database-Oxford (2016). doi: 10.1093/database/baw035

109. Goodarzi H, Liu XH, Nguyen HCB, Zhang S, Fish L, Tavazoie SF. Endogenous tRNA-Derived Fragments Suppress Breast Cancer Progression Via YBX1 Displacement. Cell (2015) 161:790-802. doi: 10.1016/j.cell.2015.02.053

110. Kim HK, Fuchs G, Wang SC, Wei W, Zhang Y, Park H, et al. A transferRNA-derived Small RNA Regulates Ribosome Biogenesis. Nature (2017) 552:57-+. doi: 10.1038/nature25005

111. Sharma U, Conine CC, Shea JM, Boskovic A, Derr AG, Bing XY, et al. Biogenesis and Function of tRNA Fragments During Sperm Maturation and Fertilization in Mammals. Science (2016) 351:391-6. doi: 10.1126/science.aad6780

112. Xie YY, Yao LP, Yu XC, Ruan Y, Li Z, Guo JM. Action Mechanisms and Research Methods of tRNA-derived Small RNAs. Signal Transduct Tar (2020) 5(1):109. doi: 10.1038/s41392-020-00217-4

113. Honda S, Loher P, Shigematsu M, Palazzo JP, Suzuki R, Imoto I, et al. Sex Hormone-Dependent tRNA Halves Enhance Cell Proliferation in Breast and Prostate Cancers. P Natl Acad Sci USA (2015) 112:E3816-25. doi: 10.1073/ pnas. 1510077112

114. Krishna S, Yim DGR, Lakshmanan V, Tirumalai V, Koh JLY, Park JE, et al. Dynamic Expression of tRNA-derived Small RNAs Define Cellular States. EMBO Rep (2019) 20(7):e47789. doi: 10.15252/embr.201947789

115. Kumar P, Anaya J, Mudunuri SB, Dutta A. Meta-Analysis of tRNA Derived RNA Fragments Reveals That They are Evolutionarily Conserved and Associate With AGO Proteins to Recognize Specific RNA Targets. $B M C$ Biol (2014) 12:78. doi: 10.1186/s12915-014-0078-0

116. Kuscu C, Kumar P, Kiran M, Su ZL, Malik A, Dutta A. tRNA Fragments (tRFs) Guide Ago to Regulate Gene Expression Post-Transcriptionally in a Dicer-independent Manner. RNA (2018) 24:1093-105. doi: 10.1261/ rna.066126.118

117. Ivanov P, Emara MM, Villen J, Gygi SP, Anderson P. Angiogenin-Induced Trna Fragments Inhibit Translation Initiation. Mol Cell (2011) 43:613-23. doi: 10.1016/j.molcel.2011.06.022 
118. Chen ZJ, Qi MJ, Shen B, Luo GZ, Wu YM, Li JX, et al. Transfer RNA Demethylase ALKBH3 Promotes Cancer Progression Via Induction of tRNA-derived Small Rnas. Nucleic Acids Res (2019) 47:2533-45. doi: 10.1093/nar/gky1250

119. Li NS, Shan NY, Lu LG, Wang ZH. tRFtarget: A Database for Transfer RNAderived Fragment Targets. Nucleic Acids Res (2021) 49:D254-60. doi: 10.1093/nar/gkaa831

120. Barbosa TD, Ingerslev LR, Alm PS, Versteyhe S, Massart J, Rasmussen M, et al. High-Fat Diet Reprograms the Epigenome of Rat Spermatozoa and Transgenerationally Affects Metabolism of the Offspring. Mol Metab (2016) 5:184-97. doi: 10.1016/j.molmet.2015.12.002

121. Lee EJ, Banerjee S, Zhou HJ, Jammalamadaka A, Arcila M, Manjunath BS, et al. Identification of piRNAs in the Central Nervous System. Rna (2011) 17:1090-9. doi: 10.1261/rna.2565011

122. Perera BPU, Tsai ZTY, Colwell ML, Jones TR, Goodrich JM, Wang K, et al. Somatic Expression of piRNA and Associated Machinery in the Mouse Identifies Short, Tissue-Specific piRNA. Epigenetics-Us (2019) 14:504-21. doi: 10.1080/15592294.2019.1600389

123. Yan Z, Hu HY, Jiang X, Maierhofer V, Neb E, He L, et al. Widespread Expression of piRNA-like Molecules in Somatic Tissues. Nucleic Acids Res (2011) 39:6596-607. doi: 10.1093/nar/gkr298

124. Jones BC, Wood JG, Chang CY, Tam AD, Franklin MJ, Siegel ER, et al. A Somatic piRNA Pathway in the Drosophila Fat Body Ensures Metabolic Homeostasis and Normal Lifespan. Nat Commun (2016) 7:13856. doi: $10.1038 /$ ncomms 13856

125. Rizzo F, Hashim A, Marchese G, Ravo M, Tarallo R, Nassa G, et al. Timed Regulation of P-Element-Induced Wimpy Testis-Interacting RNA Expression During Rat Liver Regeneration. Hepatology (2014) 60:798-806. doi: $10.1002 /$ hep. 27267

126. Ng KW, Anderson C, Marshall EA, Minatel BC, Enfield KSS, Saprunoff HL, et al. Piwi-Interacting RNAs in Cancer: Emerging Functions and Clinical Utility. Mol Cancer (2016) 15:5. doi: 10.1186/s12943-016-0491-9

127. Michel CI, Holley CL, Scruggs BS, Sidhu R, Brookheart RT, Listenberger LL, et al. Small Nucleolar Rnas U32aU33, and U35a are Critical Mediators of Metabolic Stress. Cell Metab (2011) 14:33-44. doi: 10.1016/j.cmet.2011.04.009

128. Lee JY, Harris AN, Holley CL, Mahadevan J, Pyles KD, Lavagnino Z, et al. Rpl13a Small Nucleolar RNAs Regulate Systemic Glucose Metabolism. J Clin Invest (2016) 126:4616-25. doi: 10.1172/JCI88069

129. Caputa G, Schaffer JE. RNA Regulation of Lipotoxicity and Metabolic Stress. Diabetes (2016) 65:1816-23. doi: 10.2337/db16-0147

130. Angulo MA, Butler MG, Cataletto ME. Prader-Willi Syndrome: A Review of Clinical, Genetic, and Endocrine Findings. J Endocrinol Invest (2015) 38:1249-63. doi: 10.1007/s40618-015-0312-9

131. Chamberlain SJ. Rnas of the Human Chromosome 15q11-q13 Imprinted Region. Wires RNA (2013) 4:155-66. doi: 10.1002/wrna.1150

132. Galiveti CR, Raabe CA, Konthur Z, Rozhdestvensky TS. Differential Regulation of Non-Protein Coding RNAs From Prader-Willi Syndrome Locus. Sci Rep Uk (2014) 4:6445. doi: 10.1038/srep06445

133. Falaleeva M, Surface J, Shen ML, de la Grange P, Stamm S. SNORD116 and SNORD115 Change Expression of Multiple Genes and Modify Each Other's Activity. Gene (2015) 572:266-73. doi: 10.1016/j.gene.2015.07.023

134. Burnett LC, Hubner G, Leduc CA, Morabito MV, Carli JFM, Leibel RL. Loss of the Imprinted, non-Coding Snord116 Gene Cluster in the Interval Deleted in the Prader Willi Syndrome Results in Murine Neuronal and Endocrine Pancreatic Developmental Phenotypes. Hum Mol Genet (2017) 26:4606-16. doi: $10.1093 / \mathrm{hmg} / \mathrm{ddx} 342$

135. Burnett LC, LeDuc CA, Sulsona CR, Paull D, Rausch R, Eddiry S, et al. Deficiency in Prohormone Convertase PC1 Impairs Prohormone Processing in Prader-Willi Syndrome. J Clin Invest (2017) 127:293-305. doi: 10.1172/ JCI88648

136. Hudec M, Dankova P, Solc R, Bettazova N, Cerna M. Epigenetic Regulation of Circadian Rhythm and Its Possible Role in Diabetes Mellitus. Int J Mol Sci (2020) 21(8):3005. doi: 10.3390/ijms21083005

137. Stenvers DJ, Scheer FAJL, Schrauwen P, la Fleur SE, Kalsbeek A. Circadian Clocks and Insulin Resistance. Nat Rev Endocrinol (2019) 15:75-89. doi: 10.1038/s41574-018-0122-1

138. Hughes ME, Grant GR, Paquin C, Qian J, Nitabach MN. Deep Sequencing the Circadian and Diurnal Transcriptome of Drosophila Brain. Genome Res (2012) 22:1266-81. doi: 10.1101/gr.128876.111
139. Ketchesin KD, Zong W, Hildebrand MA, Seney ML, Cahill KM, Scott MR, et al. Diurnal Rhythms Across the Human Dorsal and Ventral Striatum. P Natl Acad Sci USA (2021) 118(2):e2016150118. doi: 10.1073/pnas. 2016150118

140. Coulson RL, Yasui DH, Dunaway KW, Laufer BI, Ciernia AV, Zhu YH, et al. Snord116-dependent Diurnal Rhythm of DNA Methylation in Mouse Cortex. Nat Commun (2018) 9(1):1616. doi: 10.1038/s41467018-03676-0

141. Lassi G, Priano L, Maggi S, Garcia-Garcia C, Balzani E, El-Assawy N, et al. Deletion of the Snord116/SNORD116 Alters Sleep in Mice and Patients With Prader-Willi Syndrome. Sleep (2016) 39:637-44. doi: 10.5665/sleep.5542

142. Jimenez-Chillaron JC, Isganaitis E, Charalambous M, Gesta S, PentinatPelegrin T, Faucette RR, et al. Intergenerational Transmission of Glucose Intolerance and Obesity by In Utero Undernutrition in Mice. Diabetes (2009) 58:460-8. doi: $10.2337 / \mathrm{db} 08-0490$

143. Kaspar D, Hastreiter S, Irmler M, de Angelis MH, Beckers J. Nutrition and its Role in Epigenetic Inheritance of Obesity and Diabetes Across Generations. Mamm Genome (2020) 31:119-33. doi: 10.1007/s00335-020-09839-z

144. Patti ME. Intergenerational Programming of Metabolic Disease: Evidence From Human Populations and Experimental Animal Models. Cell Mol Life Sci (2013) 70:1597-608. doi: 10.1007/s00018-013-1298-0

145. Chen Q, Yan MH, Cao ZH, Li X, Zhang YF, Shi JC, et al. Sperm tsRNAs Contribute to Intergenerational Inheritance of an Acquired Metabolic Disorder. Science (2016) 351:397-400. doi: 10.1126/science.aad7977

146. Natt D, Kugelberg U, Casas E, Nedstrand E, Zalavary S, Henriksson P, et al. Human Sperm Displays Rapid Responses to Diet. PloS Biol (2019) 17(12): e3000559. doi: 10.1371/journal.pbio.3000559

147. Sarker G, Sun WF, Rosenkranz D, Pelczar P, Opitz L, Efthymiou V, et al. Maternal Overnutrition Programs Hedonic and Metabolic Phenotypes Across Generations Through Sperm Tsrnas. P Natl Acad Sci USA (2019) 116:10547-56. doi: 10.1073/pnas.1820810116

148. Cropley JE, Eaton SA, Aiken A, Young PE, Giannoulatou E, Ho JWK, et al. Male-Lineage Transmission of an Acquired Metabolic Phenotype Induced by Grand-Paternal Obesity. Mol Metab (2016) 5:699-708. doi: 10.1016/ j.molmet.2016.06.008

149. Cosentino C, Toivonen S, Villamil ED, Atta M, Ravanat JL, Demine S, et al. Pancreatic Beta-Cell tRNA Hypomethylation and Fragmentation Link TRMT10A Deficiency With Diabetes. Nucleic Acids Res (2018) 46:1030218. doi: $10.1093 /$ nar/gky 839

150. Igoillo-Esteve M, Genin A, Lambert N, Deser J, Pirson I, Abdulkarim B, et al. TRNA Methyltransferase Homolog Gene TRMT10A Mutation in Young Onset Diabetes and Primary Microcephaly in Humans. PloS Genet (2013) 9 (10):e1003888. doi: 10.1371/journal.pgen.1003888

151. Yin W, Rogge M, Targeting RNA. A Transformative Therapeutic Strategy. Cts Clin Transl Sci (2019) 12:98-112. doi: 10.1111/cts.12624

152. Dong YZ, Love KT, Dorkin JR, Sirirungruang S, Zhang YL, Chen DL, et al. Lipopeptide Nanoparticles for Potent and Selective siRNA Delivery in Rodents and Nonhuman Primates (Vol 111, Pg 3955, 2014). P Natl Acad Sci USA (2014) 111:5753-3. doi: 10.1073/pnas.1404711111

153. Liu CY, Su CQ. Design Strategies and Application Progress of Therapeutic Exosomes. Theranostics (2019) 9:1015-28. doi: 10.7150/thno.30853

154. Lu M, Xing HN, Xun Z, Yang TZ, Ding PT, Cai CF, et al. Exosome-Based Small RNA Delivery: Progress and Prospects. Asian J Pharm Sci (2018) 13:111. doi: 10.1016/j.ajps.2017.07.008

155. Tong XQ, Pan WH, Su T, Zhang MY, Dong W, Qi XL. Recent Advances in Natural Polymer-Based Drug Delivery Systems. React Funct Polym (2020) 148. doi: 10.1016/j.reactfunctpolym.2020.104501

Conflict of Interest: The authors declare that the research was conducted in the absence of any commercial or financial relationships that could be construed as a potential conflict of interest.

Copyright ( 2021 Jacovetti, Bayazit and Regazzi. This is an open-access article distributed under the terms of the Creative Commons Attribution License (CC BY). The use, distribution or reproduction in other forums is permitted, provided the original author(s) and the copyright owner(s) are credited and that the original publication in this journal is cited, in accordance with accepted academic practice. No use, distribution or reproduction is permitted which does not comply with these terms. 